\title{
Özel Yetenekli Öğrencilerin Yenilenebilir Enerji Kaynaklarına Yönelik Zihinsel Modellerinin Belirlenmesi *
}

\author{
Hakan Şevki AYVACI ** , Mehmet KÜÇÜK ${ }^{* * * *}$ ve Gürhan BEBEK ${ }^{* * * * *}$
}

• Geliş Tarihi: 11.06.2020 • Kabul Tarihi: 23.04.2021 • Çevrimiçi Yayın Tarihi: 08.05.2021

\section{Öz}

Araştırmanın amacı, özel yetenekli öğrencilerin yenilenebilir enerji kaynaklarına yönelik zihinsel modellerini belirlemektir. Araştırmada nitel araştırma yaklaşımları türlerinden özel durum çalışması yöntemi kullanılmıştır. Araştırmanın katılımcı grubunu Trabzon il merkezinde yer alan Bilim ve Sanat Merkezinde bireysel yetenekleri fark ettirme programında bulunan 14 öğrenci oluşturmaktadır. Katılımcılar, araştırmanın etik değerleri uyarınca S01'den S14'e kadar kodlanmıştır. Özel yetenekli öğrencilerin yenilenebilir enerji kaynaklarına yönelik zihinsel modellerini belirleme amacı doğrultusunda klinik mülakatlar yardımı ile veriler toplanmıştır. Klinik mülakatlardan elde edilen veriler içerik analizine tabi tutulmuştur. Elde edilen sonuçlara göre, katılımcıların yenilenebilir enerji kaynakları ile alternatif enerji kaynaklarını birbiri yerine ya da birlikte kullandıkları belirlenmiştir. Türleri konusunda özellikle güneş ve rüzgâr enerjisine değindikleri görülmüştür. Enerji ihtiyacı konusunda ise katılımcıların bilinçli oldukları ve küresel enerji ihtiyacının karşılanabilmesi için çalışmaların yürütülmesi gerekliliği hususlarını vurguladıkları tespit edilmiştir. Ülkemiz bağlamında değerlendirmelerinde ise ülkemizin sahip olduğu jeopolitik konum ve bölgesel farklılıkların göz önüne alınması gerektiğine dikkat çekilerek yenilenebilir enerji kaynaklarına yönelimin olması gerektiği vurgulanmıştır.

Anahtar sözcükler: özel yetenekli öğrenci, yenilenebilir enerji kaynakları, zihinsel model.

\section{Atıf:}

Ayvacı, H. Ş., Küçük, M. Ve Bebek, G. (2021). Özel yetenekli öğrencilerin yenilenebilir enerji kaynaklarına yönelik zihinsel modellerinin belirlenmesi. Pamukkale Üniversitesi Eğitim Fakültesi Dergisi, 53, 378-402.doi: 10.9779/pauefd.751509.

\footnotetext{
* İlgili çalışmanın bir kısmı "2. International Conference on Education, Technology and Science" adlı kongrede sözel bildiri olarak sunulmuştur.

** Prof. Dr., Trabzon Üniversitesi, hsayvaci@gmail.com, ORCID: 0000-0002-3181-3923

*** Prof. Dr., Recep Tayyip Erdoğan Üniversitesi, mehmetkucuk@gmail.com, ORCID: 0000-0001-5910-4099

**** Öğr. Gör. Dr., Trabzon Üniversitesi, gurhan.bebek@,gmail.com, ORCID: 0000-0003-4862-5782
} 


\section{Giriş}

Bilimin ve teknolojinin birbirlerini etkileyerek gelişim ve değişim göstermesi ve bu gelişim ve değişim unsurlarına bağlı olarak insanların bilgiye hızlı bir şekilde erişim sağlayabilme isteği (Doğan, 2011) teknolojiye yetişebilmek adına enerjiye olan ihtiyacı ortaya çıkarmaktadır (Güneş, Alat ve Gözüm, 2013). Bu enerji ihtiyacının her geçen gün artacağı ve toplumsal olarak önemli ihtiyaçlar listesinde kendisine yer bulacağı öngörülen bir gerçektir. Bu gerçeklik durumuna yönelik olarak, Özkaya (2017) tarafından yürütülen araştırmada, 2030'lu yıllarda enerji ihtiyacının yaklaşık olarak iki kat artacağı hatta 2050'li yıllarda ise bu oranın üçe katlanacağı belirtilmiştir. Belirtilen enerji ihtiyacının ilerleyen yıllarda oldukça büyük rakamlara ulaşabileceği ön görüsü göz önüne alındığında ise, yenilenemez enerji kaynakları olarak ifade edilen fosil yakıtların tükenebilir oluşu ve bu yakıtların dünya genelinde belirli bölgelerde bulunuyor olması (Mahmutoğlu, 2013) toplumların bu enerji kaynaklarına sahip olabilme ve kullanabilme gibi hususlara yönelmelerine neden olacaktır. Toplumların ilgili kaynaklara yönelim sağlaması durumuna bağlı olarak da gelecekte enerji savaşlarının yaşanabileceğini söylemek pek de yanlış olmayacaktır (T.C. Enerji ve Tabi Kaynaklar Bakanlığı, 2017). Bu doğrultuda, enerji ihtiyacı konusunda sorun yaşamamak ve geleceği felakete sürüklememek adına güneş, rüzgâr, su gibi kaynakların çeşitli yöntem ve teknikler ile işlenerek kullanılması ve yenilenebilirlik özelliği sayesinde enerji ihtiyacının giderilmesi gerekmektedir (Koç ve Şenel, 2013). Küreselleşen dünyada yer edinmek isteyen toplumlar da ilgili durumu göz önüne alarak yenilenebilir enerji kaynaklarına yönelim sağlamakta ve bilinçli bireylerin yetiştirilmesine önem vermektedir (Gül-Elmas, 2018). Bu doğrultuda yenilenebilir enerji kaynakları konusunda bireylerde farkındalık sağlamak, enerji kullanımına yönelik tasarruf ve sürdürebilirlik gibi anlayışları kazandırmak ve bireylerin kavramsal olarak bilgiye sahip olabilmesi amacıyla yenilenebilir enerji kaynakları konusu eğitim-öğretim süreci içerisinde kendisine konu alanı olarak yer bulmaktadır.

Enerji ihtiyacı konusuna yönelik hem günümüzde hem de gelecekte ciddi sorunlar çıkabilecek olması ve buna bağlı olarak da yenilenebilir enerji kaynaklarına yönelimin sağlanması gerekliliği eğitim-öğretim sürecinin ilgili durumdan etkilenmesine sebebiyet vermiştir ve konu alanında çeşitli çalışmaların yürütülmesine zemin hazırlamıştır. "Yenilenebilir enerji" anahtar kelimesini kullanarak ulusal tez merkezi incelendiğinde eğitim ve öğretim (Alagöz, 2005; Ergin, 2010), ekonomi (Ayran, 2015; Güner, 2016; Ifat, 2018; Tekeşin, 2011; Uçak, 2010; Yamak, 2006; Yaşar, 2009), elektrik ve elektronik mühendisliği (Avli-Fırış, 2018; Çemrek, 2011; Eskin, 2012; İşen, 2011; Uğurlu, 2004), endüstri 
380 H Ş, Ayvacı, M, Küçük ve G, Bebek/ Pamukkale Üniversitesi Eğitim Fakültesi Dergisi, 53, 378-402, 2021

mühendisliği (Kaymak, 2009; Öner, 2007), enerji (Angın, 2005; Can, 2011; Damgac1, 2016; Grozdev, 2010; Kar, 2008; Khalkfan, 2015; Öz, 2006; Öz, 2013; Özer, 2003; Y1lmaz, 2012), fizik mühendisliği (Sarıtaş, 2004), işletme (Nuran, 2014), kimya (Açıkgöz, 2001; Boz, 2011; Öztürk, 2010) ve makine mühendisliği (Kireç, 2009) konu alanlarında çalışmaların yürütüldükleri görülmektedir.

Eğitim-öğretim alanına yönelik yürütülen çalışmalar ele alındığında beceri ve başarı düzeyi ile konunun öğretimine yönelik model önerisi konularında olduğu ve araştırma grupları incelendiğinde ise ilköğretim öğrencileri üzerine odaklandığı belirlenmiştir. Ancak özel yetenekli olan bireylerin konu alanındaki görüş ve düşüncelerinin alındığ1 ya da enerji ihtiyacının giderilebilmesi adına proje gibi tekniklerin kullanıldığı çalışmalara rastlanmamıştır. Oysaki sahip oldukları üst bilişsel beceri ve donanımlar sayesinde (Cutts ve Moseley, 2004) problemlerin çözümüne bilimsel çözüm önerileri üretebilecek (Atak ve Atik, 2007) ve sürecin sonunda ortaya ürün çıkartabilme potansiyeline sahip olan bireylerin konu alanındaki görüşlerinin alınarak o görüşler doğrultusunda çalışmaların yürütülmesinin hem bilimsel açıdan hem ekonomik açıdan hem de toplumsal statü açısından gereklidir.

Bu bağlamda da araştırma kapsamında özel yetenekli öğrencilerin yenilenebilir enerji kaynakları kavramına yönelik zihinsel modellerini belirlemek amaçlanmıştır. İlgili amaç durumu göz önüne alındığında, özel yetenekli birey, yenilenebilir enerji kaynakları ve zihinsel model kavramlarının amaç cümlesinde yer alması nedeniyle her bir kavram aşağıda başlıklar halinde ele alınmıştır.

\section{Özel Yetenek}

Özel yetenekli bireylerin akranlarına nazaran bilişsel alanda daha üst düzey performansa sahip olduğu (Sternberg, Jarvin ve Grigorenko, 2011) ve akranlarının sahip oldukları özelliklerden ve ihtiyaçlardan daha farklı ihtiyaçları olduğu (Tomlinson ve Hockett, 2008) ifade edilmiş olmasına rağmen "özel yetenek” kavramına yönelik olarak anlaşılabilir ve keskin bir kavramsallaştırma durumu söz konusu değildir. Dolayısıyla da ilgili bireylere üstün zekâlı mı, üstün yetenekli mi yoksa özel yetenekli mi sıfatının kullanacağı konusunda spekülasyonlar oluşmaktadır. İlgili spekülasyonlara yanıt olarak 2016 yılında Millî Eğitim Bakanlığı tarafından yayınlanan yönergede bireylerin yaratıcılık, liderlik ve üst düzey performans göstergelerine sahip olmalarına bağlı olarak özel yetenekli şeklinde ifade edilmeleri gerektiği belirtilmektedir (Güney, 2018). Öte yandan belirtilen özelliklere sahip olan bireylerin eğitimöğretim süreçlerinin de özel olması gerektiği aşikâr bir gerçektir. Bu nedenle özel yetenekli bireylere yönelik hızlandırma (özel yetenekli bireylerin üstten ders alması ya da ders 
H Ş, Ayvac1, M, Küçük ve G, Bebek/ Pamukkale Üniversitesi Eğitim Fakültesi Dergisi, 53, 378-402, 2021381 atlatılmas1), zenginleştirme (eğitim-öğretim sürecinin öğretim yöntem ve teknikleri ile birlikte çeşitlendirilmesi), gruplama (sahip olunan becerilerin ve donanımların gelişimine destek olma adına özel okul ya da sınıf ortamının sağlanması) ve mentörlük (bireylerin bir araya getirilmesi sağlanarak sahip olunan özellikler açısından paylaşımın sağlanması) şeklinde eğitim hizmetleri verilmektedir (Sak, 2014). Ayrıca bireylerin eğitim-öğretim sürecini desteklemek adına bilim ve sanat merkezlerinde becerilerini destekleme, beceriler geliştirme ve beceri kazandırma gibi eğitimler verilmektedir.

\section{Yenilenebilir Enerji Kaynakları}

Yenilenebilir enerji kaynakları, isimlerinden de belli olacağı üzere yenilenebilme ve tekrar kullanılabilme özelliğine sahip olan ve tükenebilme durumu söz konusu olmayan kaynaklara verilen isimdir (Tiwari ve Mishra, 2011). Literatür incelendiğinde yenilenebilir enerji kaynaklarının güneş enerjisi, dalga enerjisi, rüzgâr enerjisi, jeotermal enerji ve biokütle enerjisi olmak üzere beş başlık altında değerlendirildiği görülmektedir (Edenhofer ve diğerleri, 2011; Førsund, 2015; Mahmutoğlu, 2013; Mertoğlu, 2019).

i) Güneş Enerjisi: Güneşin hem dünyanın sürekliliğinin sağlanmasındaki önemi hem de insan sağlığındaki etkisi göz önüne alındığında güneş ve sahip olduğu enerjinin insanlık ve bilim için ne denli önemli olduğu görülebilmektedir (Mertoğlu, 2019). Güneşin sahip olduğu enerjinin teknoloji çağı adı verilen günümüzde paneller, piller ve gün-1sı sistemleri ile birlikte günlük hayata entegre olması da ilgili önem durumunu bir kez daha gözler önüne sermektedir (Mahmutoğlu, 2013).

ii) Dalga Enerjisi: Dalga enerjisini kavramının tanımına yönelik olarak literatür incelendiğinde su enerjisi ve hidroelektrik gibi kavramların varlığı da göze çarpmaktadır. Denizlerin ya da okyanusların yüzeysel ya da derinliklerde sahip oldukları gel-git enerjilerine dalga enerjisi adı verilirken (Bıyıklı, 2018) bir akarsu ya da nehrin sahip olduğu debinin değiştirilmesine bağlı olarak elde edilen enerjiye ise su enerjisi ya da hidroelektrik adı verilmektedir (Førsund, 2015).

iii) Rüzgâr Enerjisi: Yüksek basınç alanı ile alçak basınç alanı arasında oluşan hava akımına rüzgâr ismi verilmektedir. Bu basınç alanları arasında oluşan akımın süreklilik ve tekrarlanabilirlik özelliği rüzgârın yenilenebilir enerji kaynağı olarak nitelendirilmesini sağlamaktadır (Elibüyük ve Üçgül, 2014). Yel değirmenleri, rüzgâr türbinleri ve yelkenli gemiler rüzgârın sahip olduğu bu enerjiyi ihtiyaçları doğrultusunda kullanarak kazanım elde edebilmektedirler (Kaya ve Kahraman, 2015). 
iv) Jeotermal Enerji: Yer altı sularından farklı olarak daha sıcak olan ve su buharı özelliğini barındıran jeotermal kaynaklardan elde edilen enerji jeotermal enerjidir(Yörükoğlu, 2014). Yeryüzüne çıkış sıcaklığına bağlı olarak elektrik üretimi ve ısınma ihtiyacını karşılama gibi farklı formlarda kullanılabilme gibi pozitif özelliklere sahip olan jeotermal enerjinin (Külünk, 2013) yaklaşık olarak 2000 metre derinliklerinden çıkarılması ve her bölgede bulunmaması gibi negatif özelliklerinin de göz ardı edilmeden yönelim sağlanması daha uygun olacaktır (Edenhofer ve diğerleri, 2011).

v) Biokütle Enerjisi: Bitkisel ya da hayvansal atıkların çeşitli işlemlerden (fiziksel ve kimyasal) geçirilmesi suretiyle elde edilen enerjiye verilen isimdir. Bitkisel ve hayvansal atıkların tükenme özelliğinin olmaması nedeniyle yenilenebilir enerji kaynakları içerisinde değerlendirilmektedir. Maliyetinin az olması ise kaynağın kullanımını arttırmaktadır (Edenhofer ve diğerleri, 2011).

\section{Zihinsel Model}

İlk olarak 1983 yılında Johnson Laird tarafından tanımsal olarak ifade edilen zihinsel model kavramı, insanların algılamış oldukları ya da kavramsal hale getirmiş oldukları gerçeklere yönelik analoji oluşturmaları olarak nitelendirilmiştir (İyibil-Durukan, 2019). İlgili nitelendirmeye benzer şekilde Vosniadou (1994) kişilerin üretmiş oldukları analojik gösterimler üzerinde zihinsel işlevlerin rolüne vurgu yapmıştır. Franco ve Colinvaux (2000) ise, insanların Dünyada meydana gelen olayları ve durumları anlamak amaciyla düşüncelerinde var olan içsel sunumlar olarak betimlemişlerdir. Yapılan tanımlamalar göz önüne alındığında zihinsel model kavramının; Bireylerin ilgili konu hakkında sahip oldukları ön bilgileri, düşünceleri ve kazanımlarının sonucunda zihinlerinde oluşturmuş oldukları örüntüler olarak (Greca ve Moreira, 2000) dile getirmek pek de yanlış olmayacaktır. Meydana getirilen örüntülerin soyut yapıda olması, bireylerin sahip oldukları zihinsel modellerin ortaya konulmasında sadece gözlemlenebilecek olan davranışlardan yola çıkılması ve ilgili modellerin teknolojik ve bilimsel koşullara bağlı olarak değişim göstermesi (Rapp, 2005) zihinsel modellerin dikkatli bir şekilde belirlenmesi ve değerlendirmesini birlikte getirmektedir. Özellikle ilgili modellerin soyut biçimde olması karşılaşılmamış problem durumlarına yanlış çıkarımlarda bulunmaya ve bu doğrultuda da değişmesi zor olan kavram yanılgılarına sebep olmaktadır (Eilam, 2004). Dolayısıyla da hangi konu alanında olursa olsun bireylerin zihinsel modellerinin belirlenmesine yönelik araştırmaların yürütülmesi ve zihinsel modeller içerisinde bulunan kavram yanılgılarının ve hataların giderilmesi adına önemli olacaktır. Öte yandan, zihinsel modellerin bilişsel açıdan değerlendirmeye gerek bir durum 
H Ş, Ayvac1, M, Küçük ve G, Bebek/ Pamukkale Üniversitesi Eğitim Fakültesi Dergisi, 53, 378-402, 2021383 olması ve insanların durum olay ya da olgu hakkındaki düşünceleri açısından önem durumuna sahip olmasına bağlı olarak ilgili modellerin dört özelliğinden bahsedilmektedir.

(i) Bireyler sahip oldukları zihinsel modelleri yeni durumlara transfer etmede kullanabilir.

(ii) Bireyler sahip oldukları zihinsel modelleri yeni duruma transfer ederken kullandıklarının farkında olmayabilirler. Yani zihinsel modeller "sessiz bilgiler" içerebilir.

(iii) Bireyler zihinsel modellerini meydana getirme sürecinde hem deneyimlerinden hem de bilimsel olarak ortaya konulmuş argümanlardan yararlanabilirler. Eğer böyle bir yapıya sahip olunursa orada sentez modellerden söz etmek gerekebilir.

(iv) Bireylerin sahip oldukları zihinsel modeller inanışlarından etkilenmektedir. Bireyin zihinsel modeline bakarak dünya görüşü tahmin edilebilir (Franco ve Colinvaux, 2000).

Zihinsel modellerin özellikleri ve tanımlar göz önüne alındığında bireylerin sahip oldukları zihinsel modellerde bilimsel bilginin varlığına göre sentez model ya da bilimsel model olarak adlandırabilmektedir. Eğer bireyin sahip olduğu görüşlerde deneyimler ve argümanlar yer alıyor ise sentez model; eğer bireyin sahip olduğu görüşlerde bilimsel gerçekler ve bu gerçeklere yönelik argümanalar yer alıyor ise bilimsel modelden söz etmek gerekmektedir.

\section{Yöntem}

Araştırmanın yöntem başlığı altında araştırmanın deseni, katılımcılar, veri toplama süreci ve veri toplama aracı, verilerin analizi ve inanırlık ve tutarlık çalışmalarına yönelik bilgiler sunulmuştur.

\section{Araştırmanın Deseni}

Bilimsel olarak yürütülen araştırmalarda hangi araştırma deseninin kullanılacağı araştırmanın anlamlı bir şekilde yürütülmesi ve kavramsal olarak sonuçlandırabilmesi için önemlidir. Araştırmanın amacı, problem duruları, veri toplama süreci ve bu süreçte kullanılacak olan veri toplama araçları göz önüne alınarak en uygun araştırma deseni seçilmelidir (McMillan ve Schumacher, 2006). Araştırma kapsamında, özel durum yöntemi araştırma deseni olarak seçilmiştir. Özel durum yönteminin araştırma deseni olarak seçilmesinde özel yetenekli öğrencilerin yenilenebilir enerji kaynakları kavramına yönelik zihinsel modellerinin derinlemesine incelenerek belirlemenin amaçlanmış olması ve zihinsel modellerin içeriğinde yapılacak olan değerlendirme işleminde neden sonuç ilişkisinin ortaya konulmaya çalışılmasının etkisi bulunmaktadır. Ayrıca araştırma kapsamında katılımcıların görüşünü almak için yöneltilen sorularda "Ne?", "Nasıl?” ve "Niçin?” gibi özel durum yöntemi 
384 H Ş, Ayvac1, M, Küçük ve G, Bebek/ Pamukkale Üniversitesi Eğitim Fakültesi Dergisi, 53, 378-402, 2021

içerisinde kendisine yer bulan sorularının (Çepni, 2010) yöneltiliyor olması da yöntemin seçim kriterinin uygunluğunu gözler önüne sermektedir.

\section{Katılımcılar}

Araştırmanın katılımcı grubunu Trabzon il merkezinde yer alan Bilim ve Sanat Merkezi'nde bulunan bireysel yetenekleri fark ettirme eğitim programında (BYF) yer alan 14 öğrenci oluşturmuştur. İlgili eğitim programı içerisinde yer alan katılımcılar aynı sınıf düzeyinde eğitim görmektedir. 2018-2019 eğitim öğretim içerisinde yürütülen uygulama sürecinde bilim sanat merkezinde eğitim görmekte olan BYF grubu öğrencilerinin araştırma kapsamında seçilmesinde yenilenebilir enerji kaynakları konusunun kazanım boyutunda ilgili grup düzeyinde veriliyor olmasının etkisi bulunmaktadır. Bilim sanat merkezinin BYF programı içerisinde toplam 28 öğrenci eğitim görüyor olmasına rağmen 14 öğrencinin araştırma sürecine dahil edilmesinde gönüllülük faktörünün etkisi bulunmaktadır. Etik kurallar gereği araştırmaya gönüllü katılan her bir katılımcıyla ilgili veri kaydı tutulurken, katılımcıların isimleri yerine S01, S02, ... S14 şeklindeki kodlar kullanılmıştır.

\section{Veri Toplama Süreci ve Veri Toplama Araçları}

Araştırmanın verileri katılımcılardan klinik mülakatlar ile toplanmıştır. Klinik mülakatlar, insanların durumlar, olaylar, olgular ya da konular hakkındaki sahip oldukları zihinsel düşünme süreçlerinin derinlemesine irdelenmesinde kullanılan ve sahip olduğu esnek soru sorabilme sayesinde zihinsel modelleri ortaya çıarabilen bir tekniktir (Clement, 2000). Araştırma sürecinde klinik mülakatların tercih edilmesinde zihinsel modellerin ortaya çıkarılmasında tercih ediliyor olması (Baki, Karataş ve Güven, 2002) ve esnek soru sorabilme imkânı sayesinde süreci derinlemesine inceleyebilme imkânı yaratması etkili olmuştur (Karataş ve Güven, 2003). Klinik mülakat uygulamaları yaklaşık olarak 15-20 dakikalık görüşmeler şeklinde yapılmış ve katılımcıların izinleri alınarak sesleri kaydedilmiştir. Elde edilen veriler bilgisayar ortamına aktarıldıktan sonra gerekli analiz işlemleri yerine getirilmiş ve sonrasında etik kurallar gereğince silinmiştir.

\section{Verilerin Analizi}

Klinik mülakatlar yardımı ile katılımcılardan elde edilen veriler bilgisayar destekli nitel veri analiz programı olan NVivo 10 programı kullanılarak analiz edilmiştir. Analiz sürecinde ise içerik analizi tekniği kullanılmıştır. İçerik analizi tekniği, bir konu alanı hakkında katılımcılardan elde edilen verilerin kod, kategori ve temalara ayrılması sürecini içeren ve 
H Ş, Ayvac1, M, Küçük ve G, Bebek/ Pamukkale Üniversitesi Eğitim Fakültesi Dergisi, 53, 378-402, 2021385

kavramlar arası bağlantıyı kurgularken temaları spesifik olarak oluşturmaya firsat sağlayan bir tekniktir (Büyüköztürk ve diğerleri, 2011).

\section{İnanırlık ve Tutarlık Çalışmaları}

Araştırmanın inanırlık faktörünü sağlamak adına katılımcı teyidi ve uzman görüşüne başvurulmuştur. Katılımcılardan elde edilen veriler analiz sürecinden sonra katılımcılara tekrardan sunulmuş ve teyitleri alınmıştır. Teyit sürecinden sonra ise nitel veri analizi sürecinde uzman olan bir akademisyenin görüşü alınarak araştırmanın inanırlık faktörü sağlanmaya çalışılmıştır. Araştırmanın tutarlık faktörü için iki farklı araştırmacıların yapmış olduğu analizler arasındaki uyum faktörü göz önüne alınmıştır. Nitel veri analiz sürecinde araştırmacılar ayrı ayrı kodlama işlemini gerçekleştirmişlerdir. Yapılan kodlandırmalar sonucu bir araya gelerek benzer olmayan kodlandırmalar ile görüşmeler yürüterek gözlemciler arası uyuma bakılarak tutarlık faktörü sağlanmaya çalışılmıştır.

\section{Bulgular}

Özel yetenekli öğrencilerin yenilenebilir enerji kaynakları kavramına yönelik zihinsel modellerini belirlemek amaciyla kullanılan veri toplama aracindan elde edilen veriler enerji ve enerji kaynakları kavramı, yenilenebilir enerji kaynakları türleri, yenilenebilir enerji kaynaklarına ihtiyacın sebepleri ve yenilenebilir enerji kaynaklarının kullanımı için öneriler başlıkları altında değerlendirilmiştir.

\section{Enerji ve Enerji Kaynakları Kavramları}

Özel yetenekli öğrencilere “Enerji nedir?”, "Enerji kavramını duyduğunuzda aklınıza gelen kavramlar nelerdir?”, “Enerji kaynakları nelerdir?”, “Enerji kaynakları kavramını duyduğunuzda aklınıza gelen kavramlar nelerdir?" ve "Nelere enerji kaynağı adı verilir?" soruları sorularak enerji ve enerji kaynakları kavramına yönelik görüşleri alınmıştır. Özel yetenekli öğrencilerin enerji ve enerji kaynakları kavramına yönelik görüşleri Tablo 1'de sunulmuştur. 
Tablo 1. Özel yetenekli ögrencilerin enerji ve enerji kaynakları kavramına yönelik görüşleri

\begin{tabular}{|c|c|c|c|}
\hline Tema & Kod & Frekans & Yüzde \\
\hline \multirow{5}{*}{ Enerji } & Kuvvet & 8 & 24,24 \\
\hline & Hareket & 7 & 21,21 \\
\hline & Güç & 10 & 30,30 \\
\hline & Isı ve Işık & 5 & 15,15 \\
\hline & Elektrik & 3 & 9,09 \\
\hline \multirow{5}{*}{ Enerji Kaynakları } & Fosil Yakıt Enerjisi & 7 & 18,91 \\
\hline & Güneş Enerjisi & 13 & 35,13 \\
\hline & Nükleer Enerji & 5 & 13,51 \\
\hline & Rüzgâr Enerjisi & 11 & 29,72 \\
\hline & Bor Enerjisi & 1 & 2,70 \\
\hline
\end{tabular}

Tablo 1 incelendiğinde, özel yetenekli öğrencilerin enerji kavramını kuvvet, hareket, güç, 1s1 ve ışık ve elektrik olmak üzere beş ayrı kavram ile ilişkilendirdiği; enerji kaynakları kavramını ise fosil yakıt enerjisi, güneş enerjisi, nükleer enerji, rüzgâr enerjisi ve bor enerjisi olmak üzere beş farklı kavram ile betimledikleri görülmektedir. Enerji kavramını güç kavramı ile ilişkilendiren S03 kodlu katılımcı görüşünü "Enerji denilince aklıma ilk olarak her anlamda güç geliyor” şeklinde, kuvvet kavramı ile ilişkilendiren S06 kodlu katılımcı görüşünü "Enerji bir kuvvet türüdür. Enerjinin insanlara uyguladiğı kuvvet sonucunda enerji hissedilebilir” şeklinde, hareket kavramı ile ilişkilendiren S02 kodlu katılımcı görüşünü "Hareket edildiği zaman harcanan ya da kazanılan şeyler enerjidir" şeklinde, ISı ve ışık kavramı ile ilişkilendiren S11 kodlu katılımcı görüşünü "Enerji, lsı ve ışığın yarattı̆̆ enerji ile birlikte birçok ev aleti kullanılabilir” "şeklinde ve elektrik kavramı ile ilişkilendiren S09 kodlu katılımcı ise görüşünü “Elektrik enerjisi kavramı olduğuna göre enerji elektrik ile örtüşmektedir” şeklinde ifade etmiştir. Katılımcıların enerji kavramına yönelik zihinsel modellerinde kavramsal ilişkilerin yer alıyor 
H Ş, Ayvac1, M, Küçük ve G, Bebek/ Pamukkale Üniversitesi Eğitim Fakültesi Dergisi, 53, 378-402, 2021387 olması bilimsel bilgilerin varlığını göstermektedir. Bu durum ise ilgili kavrama yönelik sentez modellere sahip olunduğunu ortaya çıkartmaktadır.

Enerji kaynakları kavramını güneş enerjisi kavramı ile ilişsilendiren S01 kodlu katılımcı görüşünü “Evlerin çatılarında bile görmeye başladığım güneş panellerini göz önüne alınca enerji kaynağı olarak güneş aklıma geliyor” şeklinde, rüzgâr enerjisi kavramı ile ilişkilendiren S07 kodlu katılımc1 görüşünü “İzmir'de bir tepenin üzerinde görmüştüm. Rüzgâr sayesinde enerji üretimi sağlanıyordu” ş̧eklinde, fosil yakıt enerjisi kavramı ile ilişkilendiren S04 kodlu katılımcı görüşünü "Enerji kaynakları olarak benzin, mazot ve doğalgaz gibi yakıtlardan bahsedebilirim” şeklinde, nükleer enerji kavramı ile ilişkilendiren S05 kodlu katılımcı görüşünü “Enerji üretimi konusunda sorun yaşayan ülkelerde nükleer enerji santrallerinin kurulumuna bağlı enerji üretilmektedir” ş̧eklinde ve bor enerjisi kavramı ile ilişkilendiren S14 kodlu katılımcı ise görüşünü “ Dünya genelinde en fazla ülkemiz toprakları içinde bulunan bor elementinden elde edilen ya da edilmesi gereken bor enerjisi" şeklinde dile getirmiştir.

Katılımcıların enerji kaynakları kavramına yönelik zihinsel modellerinde hem yenilenebilir enerji kaynaklarının hem yenilenemez enerji kaynaklarının hem de bor gibi alternatif olarak kullanılabilecek kavramın yer alıyor olması özel yetenekli öğrencilerin enerji kaynakları konusunda zihinsel modelden ziyade sentez model ya da bilimsel modellere sahip olduklarının bir göstergesi olarak ifade edilebilir.

\section{Yenilenebilir Enerji Kaynaklarının Türleri}

Özel yetenekli öğrencilere "Yenilenebilir enerji kaynakları nelerdir?”, "Yenilenebilir enerji kaynakları kavramını duyduğunuzda aklına gelen kavramlar nelerdir?" ve "Yenilenebilir enerji kaynaklarının türleri nelerdir?” soruları sorularak yenilenebilir enerji kaynaklarının türlerine yönelik görüşleri alınmıştır. Özel yetenekli öğrencilerin yenilenebilir enerji kaynaklarının türlerine yönelik görüşleri Şekil 1'de sunulmuştur. 


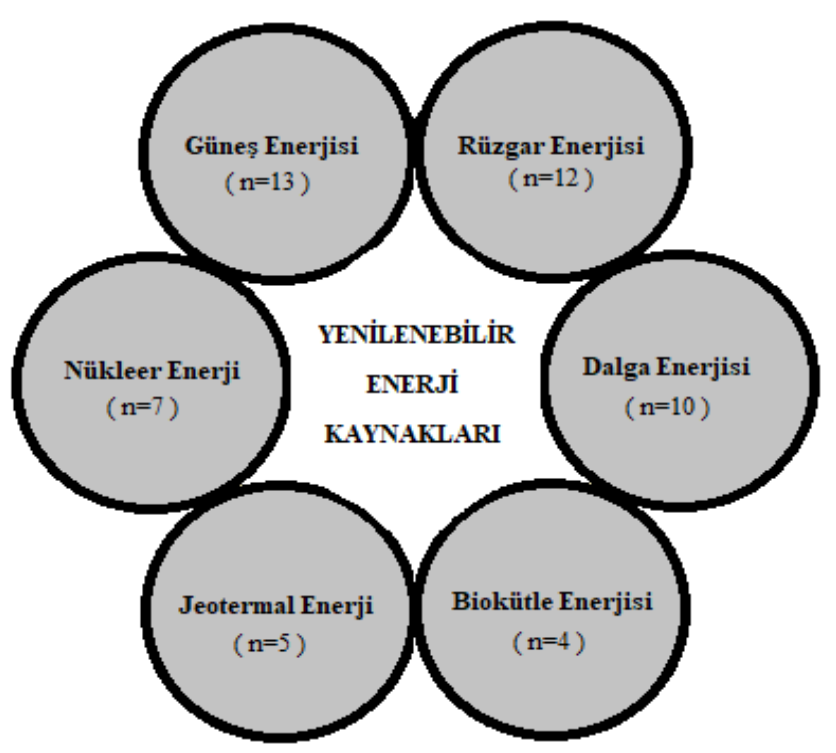

Şekil 1. Yenilenebilir enerji kaynaklarının türlerine yönelik görüşler

Şekil 1 incelendiğinde, özel yetenekli öğrencilerin yenilenebilir enerji kaynaklarının türlerine yönelik olarak görüşlerinin rüzgâr enerjisi, biokütle enerjisi, jeotermal enerji, nükleer enerji, dalga enerjisi ve güneş enerjisi olmak üzere altı ayrı alt başlık altında toplandığ görülmektedir. Yenilenebilir enerji kaynaklarının türlerine yönelik olarak güneş enerjisi kavramını dile getiren S08 kodlu katılımcı görüşünü "Yenilenebilir enerji kaynakları denilince aklıma ilk gelen şey güneştir. Güneşin sağlamış olduğu enerjinin çok önemli olduğunu düşünüyorum” şeklinde, rüzgâr enerjisi kavramını dile getiren S10 kodlu katılımcı görüşünü “Küçükken rüzgârgülleri yapardık tahtadan. Hep düşünürdüm o rüzgâr ile dönerken arkasında bir ampul bağlasak diye” şeklinde, dalga enerjisi kavramını dile getiren S12 kodlu katılımcı görüşünü "Ülkemizin üç tarafinın sular ile çevrili olması nedeniyle suyu kullanarak enerji üretimine önem vermek gerekmektedir” şeklinde, nükleer enerjisi kavramını dile getiren S13 kodlu katılımcı görüşünü “Toplumun büyük bir kısmı karşı çıksa da yenilenebilir enerji kaynaklarının başında nükleer enerji gelmektedir” ş̧eklinde, jeotermal enerji kavramını dile getiren S02 kodlu katılımcı görüşünü "Yer altı sularının etkili bir şekilde kullanılması ve enerji üretimine katkı sağlaması jeotermal enerji örnek olarak verilebilir” şeklinde ve biokütle enerjisi kavramını dile getiren S07 kodlu katılımc1 ise görüşünü "Geçen sene kimya ögretmenimizle bir proje tasarlamıştık. Laboratuvarda kullandiğımız malzemelerden artan çöplerden gaz elde etmek ve enerji olarak kullanmak şeklinde. Biokütle enerjisi de o şekilde oluyormuş" şeklinde açıklamıştır.

Katılımcıların yenilenebilir enerji kaynaklarının türlerine yönelik zihinsel modelleri yorumlandığında güneş enerjisi, dalga enerjisi, rüzgâr enerjisi, biokütle enerjisi ve jeotermal enerjinin yanı sıra nükleer enerji kavramına da değindikleri görülmektedir. Nükleer enerjinin 
H Ş, Ayvac1, M, Küçük ve G, Bebek/ Pamukkale Üniversitesi Eğitim Fakültesi Dergisi, 53, 378-402, 2021389 meydana gelebilmesi sürecinde kullanılan elementin ve meydana gelen tepkime durumu göz önüne alındığında ilgili başlık altında yer almaması gerekmektedir. Bu duruma yönelik olarak özel yetenekli öğrencilerin yenilenebilir enerji kaynaklarına yönelik zihinsel modellerinde kavram yanılgısının bulunduğu ve bu nedenle de sentez model ya da bilimsel model olarak adlandırılamayacağı ortaya konulmuştur.

\section{Yenilenebilir Enerji Kaynaklarına İhtiyacın Sebepleri}

Özel yetenekli öğrencilere "Yenilenebilir enerji kaynaklarına neden ihtiyaç duyulmaktadır?" ve "Yenilenebilir enerji kaynaklarına olan ihtiyacın sebepleri nelerdir?" sorular sorularak yenilenebilir enerji kaynaklarına olan ihtiyacın sebeplerine yönelik görüşleri alınmıştır. İlgili görüşler Şekil 2'de sunulmuştur

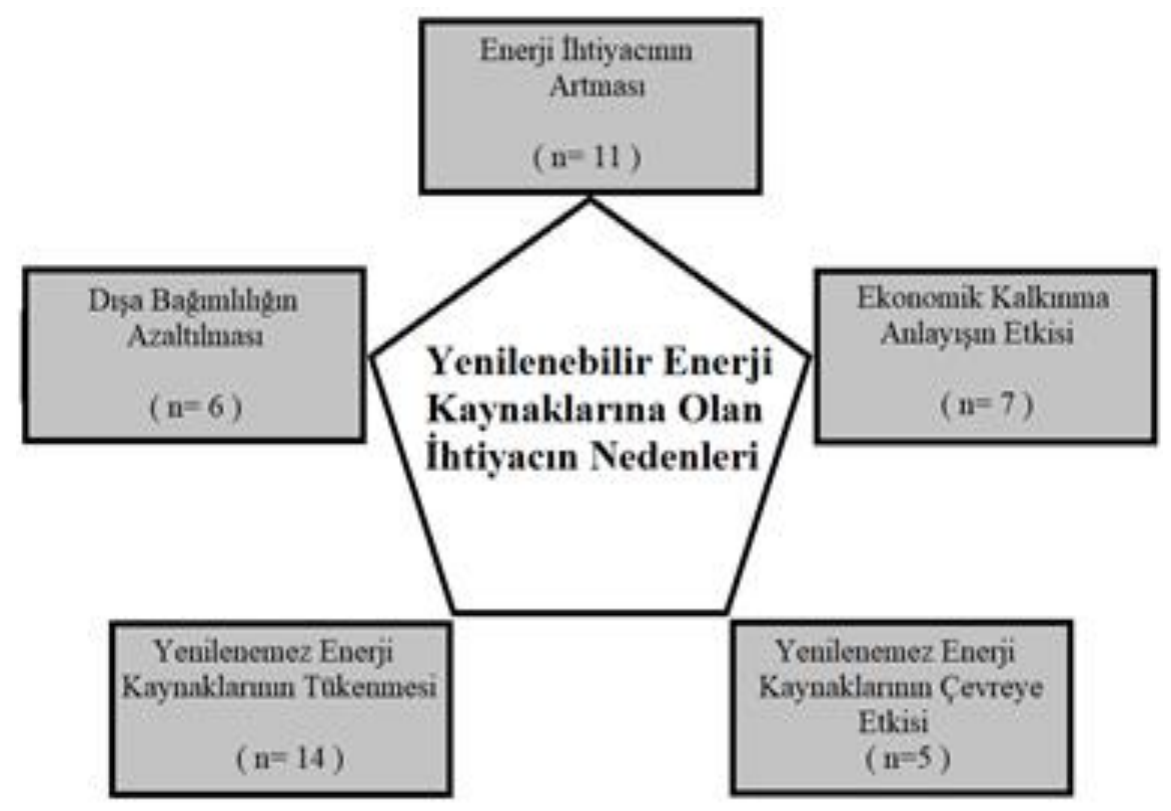

Şekil 2. Yenilenebilir enerji kaynaklarına olan ihtiyacın nedenleri yönelik görüşler

Şekil 2'de, özel yetenekli öğrencilerin yenilenebilir enerji kaynaklarına olan ihtiyacın sebeplerine yönelik görüşlerinin ekonomik kalkınma anlayışının etkisi, yenilenemez enerji kaynaklarının çevreye etkisi, yenilenemez enerji kaynaklarının tükenmesi, dışa bağımlılığın azaltılması ve enerji ihtiyacının artması olmak üzere beş alt başlık altında toplanmaktadır.

Yenilenebilir enerji kaynaklarına olan ihtiyacın sebeplerine yönelik olarak yenilenemez enerji kaynaklarının tükenmesi durumunu dile getiren S06 kodlu katılımcı görüşünü "Fosil yakıtların tükeniyor olmasl, diğer enerji kaynaklarını kullanmaya yöneltmiştir" şeklinde, enerji ihtiyacının artması durumunu dile getiren S09 kodlu katılımcı görüşünü “Teknolojik gelişmeler enerjiye olan ihtiyacı arttırmıştır. Örneğin telefon şarjı için okulda sürekli olarak prize yakın yerlerde oturmaya çalışıyorum” şeklinde, ekonomik kalkınma anlayışının 
390 H Ş, Ayvac1, M, Küçük ve G, Bebek/ Pamukkale Üniversitesi Eğitim Fakültesi Dergisi, 53, 378-402, 2021

etkisi durumunu dile getiren S12 kodlu katılımc1 görüşünü "İleri gelen ülkeler arasında olmak için para lazım. Para için ekonomiye çok fazla faktör gerekiyor. Bunlardan birisi de enerji” ş̧eklinde, dışa bağımlılığın azaltılması durumunu dile getiren S01 kodlu katılımcı görüşünü "Ülke olarak birçok alanda dışa bă̆ımlıyız. Ĕger enerji kaynaklarımız olursa bağlllıklardan uzaklaşabiliriz” şeklinde ve yenilenemez enerji kaynaklarının çevreye etkisi durumunu dile getiren S13 kodlu katılımc1 görüşünü "Petrol, mazot ve doğal gaz gibi yakıtların ortaya çıkarmış olduğu zehirli gazlar çevreye zarar vermektedir" şeklinde ifade etmiştir.

Katılımcıların yenilenebilir enerji kaynaklarına olan ihtiyacın nedenlerine yönelik zihinsel modelleri yorumlandığında yenilenemez enerji kaynaklarının tükenmesi, enerji ihtiyacının artması ve yenilenemez enerji kaynaklarının çevreye etkisi gibi bilimsel faktörlere ve dışa bağımlığı azaltma ve ekonomik kalkınma anlayışı gibi bu modelleri destekleyecek argümanlara sahip oldukları görülmektedir. Özel yetenekli öğrencilerin sahip olduğu görüşlerde bilimsel gerçekler ve bu gerçeklere yönelik argümanalar yer alıyor olması zihinsel modellerin bilimsel model haline evirildiğinin bir göstergesi olarak kabul edilebilir.

\section{Yenilenebilir Enerji Kaynaklarının Kullanımına Yönelik Öneriler}

Özel yetenekli öğrencilere "Yenilenebilir enerji kaynaklarının kullanımına yönelik ne tür öneriler söyleyebilirsiniz?”, "Yenilenebilir enerji kaynakları kullanılırken neler göz önüne alınmalıdır?" ve "Yenilenebilir enerji kaynakları daha efektif olarak nasıl kullanılabilir?" soruları sorularak yenilenebilir enerji kaynaklarının kullanımına yönelik öneriler alınmış ve Şekil 3'te sunulmuştur.

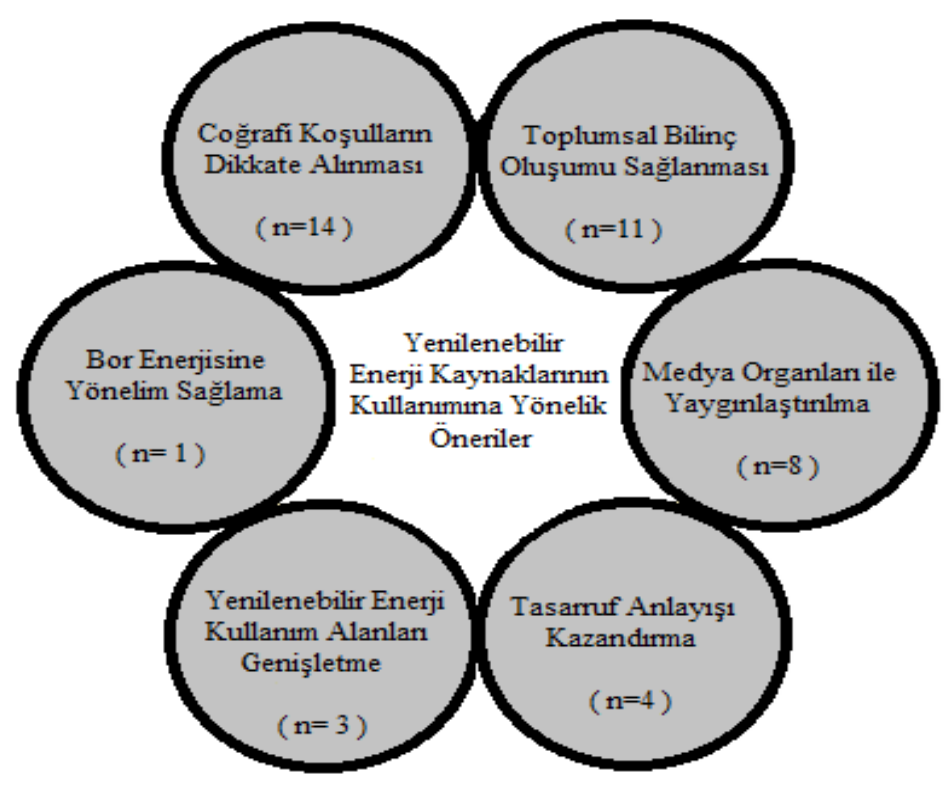

Şekil 3. Yenilenebilir enerji kaynaklarının kullanımına yönelik öneriler 
H Ş, Ayvac1, M, Küçük ve G, Bebek/ Pamukkale Üniversitesi Eğitim Fakültesi Dergisi, 53, 378-402, 2021391 Şekil 3 incelendiğinde, özel yetenekli öğrencilerin yenilenebilir enerji kaynaklarının kullanımına yönelik önerilerinin coğrafi koşulların dikkate alınması, toplumsal bilinçlendirme işleminin sağlanması, görsel ve işitsel medya organları ile yaygınlaştırma, tasarruf anlayışının kazandırılması, yenilenebilir enerji kaynaklarının kullanım alanlarının arttırılması ve bor enerjisine yönelimin sağlanması olmak üzere ayrı başlıklar altında toplanmaktadır. Yenilenebilir enerji kaynaklarının kullanımına yönelik önerilerde coğrafi koşulların dikkate alınması durumunu dile getiren S03 kodlu katılımc1 görüşünü "Bölgesel farklllıkların dikkate alınarak bölgenin sahip olduğu özelliklere göre enerji kaynaklarının kullanımı ve yaygınlaştırılması sağlanmalıdır. Deniz kenarında olan yerlerde su kullanılmalı daha yüksek kesimlerde rüzgâr kullanılmalıdır" şeklinde, toplumsal bilinçlendirme işleminin sağlanması durumunu dile getiren S11 kodlu kat1lımc1 görüşünü “Filmlerde görüyoruz hidroelektrik santralleri kurulmadan önce halkı bilinçlendirme yapıllyor. Tipkı bu şekilde yenilenebilir enerji kaynakları için topluma dersler verilmeli" şeklinde, görsel ve işitsel medya organları ile yaygınlaştırma durumunu dile getiren S08 kodlu katılımcı görüşünü "Катиyu bilinçlendirme için yapılan reklamlar da yenilenebilir enerji kaynaklarından bahsedilmesinin yararlı olacağı düşüncesindeyim” şeklinde, yenilenebilir enerji kaynaklarının kullanım alanlarının arttırılması durumunu dile getiren S01 kodlu katılımc1 görüşünü “ Sadece elektrik üretiminde değil diğer enerji türlerinin de yenilenebilir enerji kaynaklarına yönlenmek gerekir" şeklinde; tasarruf anlayışının kazandırılması durumunu dile getiren S04 kodlu katılımcı görüşünü “Enerji ihtiyacının bir şekilde giderilmesi gerekiyor yerine kullanılan yapıları daha tasarruflu nasıl kullanabiliriz düşüncesi yaygınlaştırılmalı ve kullanılmalıdır" şeklinde ve bor enerjisine yönelimin sağlanması durumunu dile getiren S04 kodlu kat1lımc1 görüşünü “Türkiye olarak sahip olduğumuz en önemli mineral olan bor kaynağına yönelim sağlanması gerekmektedir. Eminim ki bor mineralini kullanarak çeşitli alanlardaki enerji ihtiyaçları rahatlıkla karşılanabilecektir” şeklinde dile getirmiştir.

Katılımcıların yenilenebilir enerji kaynaklarının kullanımına yönelik önerileri yorumlandığında coğrafi koşulların dikkate alınması ve kullanım alanlarının genişletilmesi gibi direkt olarak yenilenebilir enerji kaynakların kullanımına yönelik; toplumsal bilinç oluşumu sağlanması, tasarruf anlayışının kazandırılması ve medya organları ile yaygınlaştırma yapılması gibi diğer paydaşların sürece dahil edilmesine yönelik ve yenilenebilir enerji kaynağ 1 olarak nitelendirilmemesine rağmen bor mineralinin kullanımının sağlanması gibi alternatif yöntemlerin değerlendirilmesine yönelik görüşler dikkat çekmektedir. 


\section{Tartıșma}

Özel yetenekli öğrencilerin yenilenebilir enerji kaynakları kavramına yönelik zihinsel modellerini belirlemek amacıyla yürütülen araştırmada elde edilen veriler enerji ve enerji kaynakları, yenilenebilir enerji kaynaklarının türleri, yenilenebilir enerji kaynaklarına olan ihtiyacın sebepleri ve yenilenebilir enerji kaynaklarının kullanımına yönelik öneriler olmak üzere dört başlık halinde sunulmuştur.

Özel yetenekli öğrencilerin enerji ve enerji kaynaklarına yönelik zihinsel modelleri incelendiğinde enerjiyi tanımlamak için güç, kuvvet ve hareket gibi çağırışımsal kavramlara yer verdikleri ve kavramsal boyutta enerjiyi tanımlayamadıkları görülmektedir. Benzer şekilde enerji kaynaklarına yönelik zihinsel modellerinde ise yenilenebilir ve yenilemez enerji kaynaklarının yanı sıra nükleer enerji ve bor gibi alternatif kaynaklar ifade edilmektedir. Enerji kaynakları konusunda Saraç ve Bedir (2014) tarafından yürütülen çalışmada, araştırmada elde edilen verilere benzer şekilde katılımcıların rüzgâr, güneş ve dalga enerjisine vurgu yaptıkları ortaya çıkmıştır. Bıyıklı (2018) tarafından öğretmen ve öğretmen adaylarının yenilenebilir enerji hakkındaki görüşlerini incelemek amacıyla yürütülen çalışmada kullanılan veri toplama aracından elde edilen veriler ile araştırmadan elde edilen veriler enerji kaynakları türleri boyutunda fosil yakıtlar ve yenilenebilir enerji kaynakları türünde paralellik göstermektedir. Benzer şekilde Cebesoy ve Karışan (2017) tarafından yürütülen çalışmada, katılımcıların çoğunlukla güneş enerjisi kavramına değindikleri belirlenmiştir. Araştırmadan elde edilen veriler ile literatürün benzerlik göstermesinde özellikle de güneş enerjisinin ön plana çıkmasında, güneşin insanlık ve hayat için öneminin yanı sıra güneş enerjisine yönelik yürütülen bilimsel çalışmaların bireylerin gözlemleyebileceği ve somutlaştırabileceği şekilde olmasının etkisinin olduğu düşünülmektedir. Hemen her bölgede evlerin çatılarının üzerinde görebilen güneş panelleri ve güneş enerjisi ile çalışan elektronik cihazların kullanımının artması gibi durumlar bu düşünceye destekler niteliktedir. $\mathrm{Bu}$ sebepten ötürü enerji kaynaklarına yönelik olarak yürütülen ya da yürütülecek olan çalışmalarda güneş kavramının ortaya çıkmasını beklemek pek de yanlış olmayacaktır.

Özel yetenekli öğrencilerin yenilenebilir enerji kaynaklarının türlerine yönelik zihinsel modelleri incelendiğinde güneş enerjisi, dalga enerjisi, rüzgâr enerjisi, biokütle enerjisi ve jeotermal enerji kavramına da değindikleri görülmektedir. Karakaya-Cırıt (2017) tarafından yürütülen çalışmada, katılımcılar güneş ve rüzgâr enerjisi kavramlarına yoğunluklu olarak değinmelerinin yanında biokütle enerjisi, jeotermal enerji, dalga enerjisi ve nükleer enerji kavramlarını da belirtmişlerdir. Gül-Elmas (2018) tarafından ortaokul öğrencilerinin 
H Ş, Ayvac1, M, Küçük ve G, Bebek/ Pamukkale Üniversitesi Eğitim Fakültesi Dergisi, 53, 378-402, 2021393 yenilenebilir enerji kaynakları konu alanındaki zihinsel yapılarının incelenmesi amacıyla yürütülen araştırmada öğrencilerin araştırma kapsamında ifade edilen yenilenebilir enerji kaynaklarının türlerine değindikleri görülmüştür. Benzer biçimde Kılıçaslan, Aymen Peker ve Gün (2011) tarafından yürütülen çalışmada, katılımcıların yenilenebilir enerji kaynakları türleri konusunda bilgi sahibi oldukları ve yenilenebilir enerji kaynakları türlerini ifade ettikleri belirlenmiştir. Araştırmadan elde edilen veriler ile literatürün benzerlik göstermesinde yenilenebilir enerji ve sürdürülebilir kalkınma anlayışına bağlı olarak yürütülen bilimsel ve ekonomik çalışmaların etkisinin olduğu düşünülmektedir. Görsel ve işitsel medya ile birlikte tasarruf anlayışının benimsenmesine yönelik kamu spotu yayınlarının oluşturulması, enerji ihtiyacı ve sürdürülebilir kalkınma anlayışının eğitim-öğretim sürecinde bir konu alanı olarak kendisine yer bulması ve toplumsal olarak küresel hedef olarak görülen ekonomik kalkınma düşüncesine bağlı olarak yürütülen uygulamalar bu düşünceyi destekler niteliktedir. Öte yandan katılımcıların zihinsel modellerinde nükleer enerji kavramına da değindikleri görülmektedir. Nükleer enerjinin meydana gelebilmesi sürecinde kullanılan elementin ve meydana gelen tepkime durumu göz önüne alındığında ilgili başlık altında yer almaması gerekirken bu başlık altında bulunması katılımcıların zihinsel modellerindeki hata olarak tespit edilmektedir.

Özel yetenekli öğrencilerin yenilenebilir enerji kaynaklarına olan ihtiyacın sebeplerine yönelik zihinsel modelleri incelendiğinde yenilenemez enerji kaynaklarının tükenmesi, enerji ihtiyacının artması ve yenilenemez enerji kaynaklarının çevreye etkisi gibi bilimsel faktörlere; dışa bağımlığı azaltma ve ekonomik kalkınma anlayışı gibi kavramları ifade etmiş olmaları da zihinsel modellerine ekonomik faktörlerin etkisini ortaya koyar niteliktedir. $\mathrm{Bu}$ durum Çakırlar (2015) tarafından ortaöğretim öğrencilerinin yenilenebilir enerji kaynakları konu alanındaki farkındalık durumlarını belirlemek amacıyla yürütülen araştırmada ülke için önem durumu vurgulanarak doğal kaynakların giderek azalması ve enerji ihtiyacının artması şeklinde belirtilmiştir. İlgili düşüncelerin ortaya çıkmasında, bilimin ve teknolojinin gelişimine bağlı olarak enerji ihtiyacının ortaya çıkması ve bu enerji ihtiyacını gidermek adına yenilenemez enerji kaynakları adı verilen fosil yakıtların tercih edilerek sürecin yürütülmesinin etkisinin olduğu düşünülmektedir. Teknoloji ya da bilim çağı adı verilmekte olan dönem içerisinde insanların kullanıldıkları teknolojik araç gereçler olan telefonlardan bilgisayarlara, bilgisayarlardan beyaz eşyaya kadar tüm materyallerde enerjiye ihtiyaç duyulmaktadır (Deviren, İlkılıç ve Aydın, 2017). İlgili ihtiyaç durumunu karşılayabilmek adına öncelikli olarak fosil yakıtların tercih ediliyor olması tükenebilirlik, yenilenemezlik, 
394 H Ş, Ayvac1, M, Küçük ve G, Bebek/ Pamukkale Üniversitesi Eğitim Fakültesi Dergisi, 53, 378-402, 2021

kullanışlılık ve verimlilik gibi kavramları ortaya çıkarmaktadır. İlgili kavramların toplumlara yaratmış olduğu külfet göz önüne alındığında ise toplumların fosil yakıtlardan uzaklaşarak güneş ve rüzgâr gibi yenilenebilir kaynaklara yönelim sağladığı söylenebilir (Üçgül ve Elibüyük, 2016). Dolayısıyla da hem külfeti ortadan kaldırmak hem de bilimsel ve ekonomik açıdan kalkınarak siyasal açıdan da söz sahibi olmak isteyen toplumlar yenilenebilir enerji kaynaklarına yönelmektedirler (Altun ve İşleyen, 2018; Özcan, Ünlüsoy ve Eren, 2017).

Özel yetenekli öğrencilerin yenilenebilir enerji kaynaklarının kullanımına yönelik önerileri incelendiğinde coğrafi koşulların dikkate alınması ve kullanım alanlarının genişletilmesi gibi direkt olarak yenilenebilir enerji kaynakların kullanımına yönelik ve toplumsal bilinç oluşumu sağlanması, tasarruf anlayışının kazandırılması ve medya organları ile yaygınlaştırma yapılması gibi diğer paydaşların sürece dahil edilmesine yönelik öneriler dikkat çekmektedir. Enerji ihtiyacını giderebilmek amacıyla yenilenebilir enerji kaynaklarına yönelimin doğru ve uygulanabilir bir şekilde olabilmesi için sahip olunan coğrafi koşulların dikkate alınması gerekmektedir. Özellikle de üç taraflı denizler ile çevrili olan ülkemizde dalga enerjisini kullanarak enerji üretiminin sağlanması gerektiğini söylemek pek de yanlış olmayacaktır. Benzer biçimde sıcaklığın yüksek seyrettiği Akdeniz ve Güneydoğu Anadolu bölgelerinde güneş enerjisi (güneş panelleri vb.) ve rüzgâr açısından potansiyel olarak iyi bir yere sahip olan Ege Bölgesinde rüzgâr enerjisi (rüzgâr tribünleri vb.) ile enerji ihtiyacının giderilmesi amacıyla yürütülen uygulamaların sürekliliğinin sağlanması ve donanım ve alt yapı olanakları açısından gerekli şartların sağlanarak enerji üretim sürecinin devam ettirilmesi ülkemizin bugünü ve geleceği açısından önem arz etmektedir. Ayrıca yenilenebilir enerji kaynağı olarak nitelendirilmemesine rağmen bor mineralinin kullanımının sağlanması gibi alternatif yöntemlerin değerlendirilmesine yönelik zihinsel modellerin varlığı da dikkat çekici boyuttadir.

\section{Sonuç}

Özel yetenekli öğrencilerin enerji ve enerji kaynakları konusundaki düşünceleri incelendiğinde, anlamsal ve kavramsal açıdan zihinsel modellerinde eksikliklerin ve hataların olduğu görülmektedir. Bu sorunun üstesinden gelebilmek adına zihinsel modellerin düzenli hale getirilerek bilimsel birer model olabilmeleri adına eğitim-öğretim sürecinde destek eğitimlerinin verilmesi önerilmektedir.

- Özel yetenekli öğrencilerin yenilenebilir enerji kaynaklarının türleri konusundaki görüşlerinde güneş enerjisi, rüzgâr enerjisi, biokütle enerjisi, jeotermal enerji, dalga enerjisi 
H Ş, Ayvac1, M, Küçük ve G, Bebek/ Pamukkale Üniversitesi Eğitim Fakültesi Dergisi, 53, 378-402, 2021395 ve nükleer enerji kavramlarına farklı oranlarda olsa dahi değindikleri görülmektedir. İlgili öğrencilerin türlerin isimlerini kavramsal olarak ifade etmek ile kalmayıp bu kavramların enerji ihtiyacının giderilmesi önemini içselleştirmek adına proje uygulamalarının yürütülmesi önerilmektedir.

- Özel yetenekli öğrencilerin görüşlerine göre yenilenebilir enerji kaynaklarına olan ihtiyacın sebeplerinde enerji ihtiyacının artması ve kullanılan enerji kaynaklarının tükenmesi durumları ortaya çıkarılmaktadır. Artan enerji ihtiyacını karşılamak adına yenilenebilir enerji kaynaklarına yönelimin sağlanmasının yanı sıra sürdürebilir kalkınma anlayışının benimsetilmesi ve tasarruf düşüncesinin toplumsal olarak anlamlı bir şekilde zihinlerde yapılandırılması önerilmektedir.

- Özel yetenekli öğrencilerin yenilenebilir enerji kaynaklarının kullanımına yönelik önerilerinde kaynakların daha verimli ve etkili bir biçimde kullanabilmesi adına coğrafi koşulların dikkate alınması ve toplumsal bilinçlendirmenin sağlanması önerilmiştir. $\mathrm{Bu}$ duruma yönelik olarak ilgili konu alanında çalışma yürütmeyi planlayan araştırmacıların ifade edilen önerileri dikkate alıp çalışmalar yürütmelerinin faydalı olacağı düşünülmektedir.

Etik Kurul İzin Bilgisi: Bu araştırma, Trabzon Üniversitesi Sosyal ve Beşerî Bilimler Araştırma ve Yayın Etik Kurulu'ndan 13 /11/2018 tarih 81614018-50 sayılı kararı ile izin alınarak yürütülmüştür.

Yazar Çıkar Çatışması Bilgisi: Yazarların beyan edeceği bir çıkar çatışması yoktur. Yazar Katkısı: Yazarlar makaleye eşit katkı sağlamış olduklarını beyan ederler. 
396 H Ş, Ayvac1, M, Küçük ve G, Bebek/ Pamukkale Üniversitesi Eğitim Fakültesi Dergisi, 53, 378-402, 2021

\section{Kaynakça}

Açıkgöz, Ç. (2001). Keten tohumunun alternatif enerji kaynağı olarak incelenmesi. Yayımlanmamış doktora tezi, Anadolu Üniversitesi, Eskişehir.

Alagöz, B. (2005). İlköğretim II. kademe sosyal bilgiler dersinde yenilenebilir (alternatif) enerji kaynaklarının öğretimine ilişkin bir ünite modeli önerisi. Yayımlanmamış yüksek lisans tezi, Gazi Üniversitesi, Ankara.

Altun, Y. ve İşleyen, Ş. (2018). Bazı OECD ülkelerinde yenilenebilir enerji kaynaklarından elektrik üretimine yönelim üzerine ampirik bir çalışma. Atatürk Üniversitesi Sosyal Bilimler Enstitüsü Dergisi, 22(3), 1577-1590.

Angın, D. (2005). Aspir (Charthamus tinctorius L.) tohumu pres küspesinin alternatif enerji kaynağı olarak değerlendirilmesi. Yayımlanmamış doktora tezi, Eskişehir Osmangazi Üniversitesi, Eskişehir.

Atak, M. ve Atik, İ. (2007). Örgütlerde sürekli eğitimin önemi ve öğrenen örgüt oluşturma sürecine etkisi. Havacılık ve Uzay Teknolojileri Dergisi, 3(1), 63-70.

Avli-Fırış, F. (2018). Sinyalizasyon sistemleri için alternatif enerji üretimi. Yayımlanmamış yüksek lisans tezi. Kahramanmaraş Sütçü İmam Üniversitesi, Kahramanmaraş.

Ayran, K. (2015). Türkiye'de alternatif enerji kaynaklarının ekonomik açıdan irdelenmesi. Yayımlanmamış yüksek lisans tezi, Çankırı Karatekin Üniversitesi, Çankırı.

Baki, A., Karataş, İ. ve Güven, B. (2002, Eylül). Klinik mülakat yöntemi ile problem çözme becerilerinin değerlendirilmesi. V. Ulusal Fen Bilimleri ve Matematik Eğitimi Kongresi, ODTÜ, Ankara.

Bıyıklı, D. (2018). Öğretmen ve öğretmen adaylarının yenilenebilir enerji kaynaklarına yönelik görüşlerinin incelenmesi. Yayımlanmamış yüksek lisans tezi, Mersin Üniversitesi, Mersin.

Boz, O. H. (2011). Günümüzün alternatif enerji kaynă̆ı: Fotovoltaik güneş pilleri. Yayımlanmamış yüksek lisans tezi, Balıkesir Üniversitesi, Balıkesir.

Büyüköztürk, S., Kılıç Çakmak, E., Akgün, O. E., Karadeniz, S. ve Demirel, F. (2011). Bilimsel araştırma yöntemleri (8.Baskı). Ankara: PEGEM Akademi.

Can, S. (2011). Alternatif enerji kaynaklarının yönetilmesi: Çanakkale ili örneği. Yayımlanmamış yüksek lisans tezi, Çanakkale Onsekiz Mart Üniversitesi, Çanakkale. 
H Ş, Ayvac1, M, Küçük ve G, Bebek/ Pamukkale Üniversitesi Eğitim Fakültesi Dergisi, 53, 378-402, 2021397

Cebesoy, Ü. B. ve Karışan, D. (2017). Fen bilgisi öğretmen adaylarının yenilenebilir enerji kaynaklarına yönelik bilgilerinin, tutumlarının ve bu kaynakların öğretimi konusundaki özyeterlik algılarının incelenmesi. YYÜ Ĕ̆itim Fakültesi Dergisi, 14(1), 1377-1415.

Clement, J. (2000). Analysis of clinical interviews: Foundation and model viability. In A. E. Kelly \& R. Lesh (Eds.), Handbook of research design in mathematics and science education (pp. 547-589). New Jersey: Lawrence Erlbaum.

Cutts, N. E. \& Moseley, N. (2004). Üstün zekâlı ve üstün yetenekli çocukların eğitimi: Ulusun en büyük kaynaklarından birinin harcanması nasıl önlenir, (Çeviren: İsmail Ersevim). İstanbul: Özgür Yayınları.

Çakırlar, E. (2015). Ortaöğretim öğrencilerinin yenilenebilir enerji kaynakları konusundaki farkındalık düzeylerinin belirlenmesi. Yayımlanmamış yüksek lisans tezi, Hacettepe Üniversitesi, Ankara.

Çemrek, Ş. (2011). Kayısı çekirdeği ve kestane kabuklarının alternatif enerji kaynă̆ı olarak değerlendirilmesi. Yayımlanmamış yüksek lisans tezi., Eskişehir Osmangazi Üniversitesi, Eskişehir.

Çepni, S. (2010). Araştırma ve proje çalışmalarına giriş. Trabzon: Celepler Matbaacılık.

Damgacı, E. (2016). Alternatif enerji kaynaklarının sezgisel bulanık Topsis yöntemiyle değerlendirilmesi. Yayımlanmamış yüksek lisans tezi, Gazi Üniversitesi, Ankara.

Deviren, H., İlkılıç, C. ve Aydın, S. (2017). Biyogaz üretiminde kullanılabilen materyaller ve biyogazın kullanım alanları. Batman Üniversitesi Yaşam Bilimleri Dergisi, 7(2), 7989.

Doğan, Y. (2011). Fen ve teknoloji derslerinde yapılması öngörülen yapılandırmacı etkinliklerin uygulanma sıklığı. Kuramsal Eğitimbilim, 4(1), 18-37.

Edenhofer, O., Pichs-Madruga, R., Sokona, Y., Seyboth, K., Kadner, S., Zwickel, T., ... \& Matschoss, P. (2011). Renewable energy sources and climate change mitigation: Special report of the intergovernmental panel on climate change. New York: Cambridge University Press.

Eilam, B. (2004). Drops of water and of soap solution: Students' constraining mental models of the nature of matter. Journal of Research in Science Teaching, 41(10), 970-993. 
398 H Ş, Ayvac1, M, Küçük ve G, Bebek/ Pamukkale Üniversitesi Eğitim Fakültesi Dergisi, 53, 378-402, 2021

Elibüyük, U. ve Üçgül, İ. (2014). Rüzgâr türbinleri, çeşitleri ve rüzgâr enerjisi depolama yöntemleri. Süleyman Demirel Üniversitesi Yekarum e-Dergi, 2(3), 1-14.

Ergin, A. (2010). Alternatif enerji kaynakları ĕgitim programının ilköğretim 7.sınıf ögrencilerinin problem çözme becerileri ve başarı düzeylerine etkisi. Yayımlanmamış yüksek lisans tezi, Yeditepe Üniversitesi, İstanbul.

Eskin, A. (2012). Alternatif enerji sistemlerinde kullanılan çok seviyeli eviricilerin incelenmesi. Yayımlanmamış yüksek lisans tezi, Yıldız Teknik Üniversitesi, İstanbul.

Førsund, F. R. (2015). Hydropower economics. New York: Springer.

Franco, C. \& Colinvaux, D. (2000). Grasping mental models. In J. K. Gilbert, \& C. J. Boulter (Eds.), Developing models in science education (pp. 93-118). New York: Springer.

Greca, I. M. \& Moreira, M. A. (2000). Mental models, conceptual models, and modelling. International Journal of Science Education, 22(1), 1-11.

Grozdev, M. (2010). Alternatif enerji kaynakları: Güneş enerjisi ve güneş pilleri. Yayımlanmamış yüksek lisans tezi, İstanbul Üniversitesi, İstanbul.

Gül-Elmas, Ö. (2018). 6. sınıf öğrencilerinin “yenilenebilir enerji” konusundaki bilişsel yapılarının incelenmesi. Yayımlanmamış yüksek lisans tezi, Mersin Üniversitesi, Mersin.

Güner, C. (2016). Cari açık ve işsizlik sorununun alternatif enerji kaynakları ile çözümü, Türkiye örneği. Yayımlanmamış yüksek lisans tezi, Cumhuriyet Üniversitesi, Sivas.

Güneş, T., Alat, K. ve Gözüm, C. A. İ. (2013). Fen öğretmeni adaylarına yönelik yenilenebilir enerji kaynakları tutum ölçeği: Geçerlilik ve güvenirlik çalışması. Eğitim Bilimleri Araştırma Dergisi, 3(2), 269-289.

Güney, K. K. (2018). Üstün yetenekli öğrenciler için geliştirilen farklılaştırılmış bilimsel araştırma yöntemleri programının değerlendirilmesi. Yayımlanmamış doktora tezi, Karadeniz Teknik Üniversitesi, Trabzon.

Ifat, M. (2018). Domestic energy poverty and willingness to pay for alternative energy: The case of Pakistan. Yayımlanmamış yüksek lisans tezi, Sabancı Üniversitesi, İstanbul.

İşen, E. (2011). Alternatif enerji kaynakları için şebekeye bağlı düşük harmonikli ve yüksek verimli üç fazlı inverter sisteminin geliştirilmesi. Yayımlanmamış doktora tezi, Yıldız Teknik Üniversitesi, İstanbul. 
H Ş, Ayvac1, M, Küçük ve G, Bebek/ Pamukkale Üniversitesi Eğitim Fakültesi Dergisi, 53, 378-402, 2021399

İyibil-Durukan, Ü. G. (2019). Elektrik akımı konusuna yönelik tasarlanan adidaktik öğrenme ortamlarının lisans öğrencilerinin zihinsel modellerinin gelişimine etkisi. Yayımlanmamış doktora tezi, Trabzon Üniversitesi, Trabzon.

Kar, Y. (2008). Çörekotu (Nigella sativa L.) tohumunun doğal antioksidan ve alternatif enerji kaynă̆l olarak incelenmesi. Yayımlanmamış doktora tezi, Selçuk Üniversitesi, Konya.

Karakaya-Cırıt, D. (2017). Fen bilgisi öğretmen adaylarının yenilenebilir enerji kaynaklarına ilişkin bilgileri. Turkish Journal of Educational Studies, 21-43.

Karataş, İ. ve Güven, B. (2003). Problem çözme davranışlarının değerlendirilmesinde kullanılan yöntemler: Klinik mülakatın potansiyeli. İlköğretim Online E-Dergi, 2, 29.

Kaya, T. \& Kahraman, C. (2010). Multicriteria renewable energy planning using an integrated fuzzy VIKOR \& AHP methodology: The case of Istanbul. Energy, 35(6), 2517-2527.

Kaymak, M. E. (2009). 20. yüzyılda alternatif enerji kaynaklarının gelişimi ve buna paralel olarak otomobil tasarımına etkileri. Yayımlanmamış yüksek lisans tezi, Anadolu Üniversitesi, Eskişehir.

Khalkfan, O. M. (2015). Hareket halindeki taşıtların tekerlek bask kuvvetlerinden alternatif enerji elde edilmesi. Yayımlanmamış doktora tezi, Selçuk Üniversitesi, Konya.

Kılıçaslan, M., Aymen-Peker, E. ve Gün, F. (2011, Ekim). Yenilenebilir enerji kaynaklarının çevreye olan katkısına ilişkin ilkögrretim ögrrenci görüşleri: Samsun ili örneği. Samsun Sempozyumu, Samsun.

Kireç, L. (2009). Taşıtlar için alternatif enerji sistemi olan polimer elektrolit membran yakıt pili yapımı ve parametrik olarak incelenmesi. Yayımlanmamış yüksek lisans tezi, Gazi Üniversitesi, Ankara.

Koç, E. ve Şenel, M. C. (2013). Dünyada ve Türkiye'de enerji durumu genel değerlendirme. Mühendis ve Makine, 54(639), 32-44.

Külünk, İ. (2013). Enerji verimliliği ve karbon salınımı çerçevesinde enerji tüketimi ve ekonomik büyüme ilişkisi: Türkiye örneği. Yayımlanmamış yüksek lisans tezi, Abant İzzet Baysal Üniversitesi, Bolu. 
400 H Ş, Ayvac1, M, Küçük ve G, Bebek/ Pamukkale Üniversitesi Eğitim Fakültesi Dergisi, 53, 378-402, 2021

Mahmutoğlu, M. (2013). Türkiye elektrik sektöründe yenilenebilir enerjinin rolü. Yayınlanmamış yüksek lisans tezi, Gazi Üniversitesi, Ankara.

McMillan, J. H. \& Schumacher, S. (2006). Research in education: Evidence-based inquiry. Boston: Pearson Education.

Mertoğlu, Ç. (2019). Üniversite ögrencilerinin yenilenebilir enerji kaynakları konusundaki farkındalık düzeylerinin belirlenmesi. Yayımlanmamış yüksek lisans tezi, Ondokuz Mayıs Üniversitesi, Samsun.

Nuran, M. (2014). Gemi makineleri işletme mühendisliği: Alternatif enerji kaynakları için karşılaştırmalı maliyet analizi. Yayımlanmamış doktora tezi, Dokuz Eylül Üniversitesi, İzmir.

Öner, U. (2007). Türkiye'nin alternatif enerji kaynaklarl ve bor madeninin endüstride kullanım alanlarının araştırılması. Yayımlanmamış yüksek lisans tezi, İstanbul Ticaret Üniversitesi, İstanbul.

Öz, E. (2013). Binalar için alternatif enerji opsiyonlarl ve sürdürülebilirlik değerlendirilmesinin analizi. Yayımlanmamış yüksek lisans tezi, Süleyman Demirel Üniversitesi, Isparta.

Öz, M. E. U. (2006). Bursa için konutlarda enerji tüketim karakteristiklerinin belirlenmesi ve bu konutlar için yakıt hücreleri ile alternatif enerji tüketim sistemlerinin karşılaştırılması. Yayımlanmamış doktora tezi, Uludağ Üniversitesi, Bursa.

Özcan, E. C., Ünlüsoy, S. ve Tamer, E. (2017). ANP ve TOPSIS yöntemleriyle Türkiye'de yenilenebilir enerji yatırım alternatiflerinin değerlendirilmesi. Selçuk Üniversitesi Mühendislik, Bilim ve Teknoloji Dergisi, 5(2), 204-219.

Özer, S. (2003). Bursa'da hava kirliliği sorunu ve alternatif enerji kaynaklarl. Yayımlanmamış yüksek lisans tezi, Uludağ Üniversitesi, Bursa.

Özkaya, S. Y. (2017). Yenilenebilir enerji kaynakları. Ankara: Türkiye Cumhuriyeti Dışişleri Bakanlığı.

Öztürk, Z. (2010). Vinil piridin içeren metal organik kafes yapılı bileşiklerin sentezi ve alternatif enerji kaynă̆ı hidrojen depolama özellikleri. Yayımlanmamış yüksek lisans tezi, Ondokuz Mayıs Üniversitesi, Samsun. 
H Ş, Ayvac1, M, Küçük ve G, Bebek/ Pamukkale Üniversitesi Eğitim Fakültesi Dergisi, 53, 378-402, 2021401

Rapp, D. N. (2005). Mental models: Theoretical issues for visualizations in science education. In J. K. Gilbert (Ed.), Visualization in science education (pp. 43-60). Netherlands.

Sak, U. (2014). Üstün zekâlılar: Özellikleri, tanılanmaları, eğitimleri. (4. Basım). Ankara: Vize Yayıncilık.

Saraç, E. ve Bedir, H. (2014). Sınıf öğretmenlerinin yenilenebilir enerji kaynakları ile ilgili algılamaları üzerine nitel bir çalışma. KHO Bilim Dergisi,24 (1), 19-45.

Sarıtaş, F. (2004). Hidrojenin alternatif enerji kaynağı olarak gelecekteki önemi, uygulama alanları ve yakıt hücrelerindeki kullanımı. Yayımlanmamış yüksek lisans tezi, Eskişehir Osmangazi Üniversitesi, Eskişehir.

Sternberg, R. J., Jarvin, L. \& Grigorenko, E. L. (2011). Explorations in giftedness. Cambridge University Press: New York.

T.C. Enerji ve Tabi Kaynaklar Bakanlığ (2017). Dünya ve Türkiye Enerji ve Tabii Kaynaklar Görünümü, Ankara.

Tekeşin, C. (2011). Türkiye için alternatif enerji kaynaklarına yönelik ödeme istekliliğinin hesaplanması. Yayımlanmamış yüksek lisans tezi, Hacettepe Üniversitesi, Ankara.

Tiwari, G. N. \& Mishra, R. K. (2012). Advanced renewable energy sources. London: RSC Publishing.

Tomlinson, C. A. \& Hockett, J. A. (2008). Instructional strategies and programming models for gifted learners. In F. A. Karnes \& K. R. Stephens (Eds.), Achieving excellence: Educating the gifted and talented (pp. 154-169). Upper Saddle River, NJ: Pearson.

Uçak, S. (2010). Sürdürülebilir kalkınma bağlamında alternatif enerji ve enerji üretimi büyüme ilişkisi: Panel-veri analizi. Yayımlanmamış doktora tezi, Kocaeli Üniversitesi, Kocaeli.

Uğurlu, M. (2004). Alternatif enerji kaynakları, rüzgâr enerjisi ve gerçekleştirilmesi. Yayımlanmamış yüksek lisans tezi, Sakarya Üniversitesi, Sakarya.

Üçgül, İ. ve Elibüyük, U. (2016). Yenilenebilir enerji kaynakları ve enerji jeopolitiği. Anka edergi Teknoloji ve Sosyal Bilimler Dergisi, 2(1), 26-33.

Vosniadou, S. (1994). Capturing and modelling the process of conceptual change. Learning and Instruction, 4, 45-69. 
402 H Ş, Ayvac1, M, Küçük ve G, Bebek/ Pamukkale Üniversitesi Eğitim Fakültesi Dergisi, 53, 378-402, 2021

Yamak, T. (2006). Türkiye'nin alternatif enerji kaynakları potansiyeli ve ekonomik analizleri. Yayımlanmamış yüksek lisans tezi, Marmara Üniversitesi, İstanbul.

Yaşar, B. (2009). Alternatif enerji kaynă̆ı olarak biyodizel üretim ve kullanım olanaklarının Türkiye tarımı ve AB uyum süreci açısından değerlendirilmesi. Yayımlanmamış doktora tezi, Çukurova Üniversitesi, Adana.

Yılmaz, A. (2012). Türkiye'de sektörel enerji tüketimini etkileyen faktörler ve alternatif enerji politikaları. Yayımlanmamış doktora tezi, Adnan Menderes Üniversitesi, Aydın.

Yörükoğlu, H. (2014). Yenilenebilir enerji kaynakları risklerinin Fuzzy-Fmea yöntemi ile analizi. Yayımlanmamış yüksek lisans tezi, Kocaeli Üniversitesi, Kocaeli. 


\title{
Determination of Mental Models of Gifted Students About Renewable Energy
}

\section{Resources *}

Hakan Şevki AYVACI**, Mehmet KÜÇÜK ${ }^{* * *}$ and Gürhan BEBEK ${ }^{* * * *}$

- Received: 11.06.2020 • Accepted: 23.04.2021 • Online First: 08.05.2021

\begin{abstract}
The purpose of this study is to determine the mental models of gifted students towards renewable energy resources. The case study method, one of the qualitative research approaches, was used in this study. The participants of this study are 14 students studying in an individual difference program from Science and Art Center in Trabzon. The participants of this study were coded as S01, S02,... S14 following ethical rules. Clinical interviews were conducted to determine the participants' mental models regarding the concept of "renewable energy resources." The data obtained were analyzed by content analysis which is one of the qualitative data analysis techniques. According to the analysis results, it was determined that the participants used the concept of renewable energy resources together with the concept of alternative energy sources. It was determined that they mostly talk about wind energy and solar energy. Also, gifted students are conscious of their energy needs. In this context, studies should be carried out to meet the need for universal energy. In addition, orientation to renewable energy resources should be provided by considering the geographical conditions and regional differences.
\end{abstract}

Keywords: gifted student, renewable energy resources, mental models

\section{Cited:}

Ayvaci, H. S., Kucuk, M \& Bebek, G. (2021). Determination of mental models of gifted students about renewable energy resources. Pamukkale University Journal of Education, 53, 378402.doi: 10.9779/pauefd. 751509 .

\footnotetext{
* This manuscript is from presented at a 2. International Conference on Education, Technology and Science and not partially and completely published.

** Prof. Dr., Trabzon University, hsayvaci@gmail.com, ORCID: 0000-0002-3181-3923

*** Prof. Dr., Recep Tayyip Erdoğan University, mehmetkucuk@gmail.com, ORCID: 0000-0001-5910-4099

**** Öğr. Gör. Dr., Trabzon University, gurhan.bebek@gmail.com, ORCID: 0000-0003-4862-5782
} 


\section{Introduction}

The development and change of science and technology by influencing each other and people's desire to gain access to information quickly (Dogan, 2011) reveals the need for energy (Gunes, Alat \& Gozum, 2013). It is an anticipated fact that energy needs will increase day by day, and It will find a place for itself in the list of socially important needs. Regarding this reality situation, in the research conducted by Ozkaya (2017), it is stated that the energy need will increase approximately twice in the 2030s and even triple in the 2050s. Considering that the specified energy need may reach large numbers in the coming years, the fact that fossil fuels, which are expressed as non-renewable energy resources, are exhaustible and these fuels are available in certain regions around the world (Mahmutoglu, 2013) will cause societies to turn to issues such as owning and using these energy resources. It can be said that energy wars may occur in the future because societies provide orientation to energy resources (Republic of Turkey Ministry of Energy and Natural Resources, 2017). Accordingly, societies should use resources such as sun, wind, and water by processing them with various methods and turning to renewable energy resources not to have problems regarding energy needs (Koc \& Senel, 2013). Societies that want to take place in the globalizing world also tend to renewable energy resources and raise conscious individuals (Gul-Elmas, 2018). Depending on this importance, the education and training process should be organized to raise awareness of individuals on renewable energy resources, gain an understanding of energy use, and help them become conscious. The fact that serious problems may arise regarding the energy needs both today and in the future and the orientation towards renewable energy resources caused the education process to be affected by the relevant situation and paved the way for the execution of various studies.

When the national thesis center is examined using the keyword "renewable energy", studies were carried out in the fields of education (Alagoz, 2005; Ergin, 2010), economy (Ayran, 2015; Guner, 2016; Ifat, 2018; Tekesin, 2011; Ucak, 2010; Yamak, 2006; Yasar, 2009), electrical and electronic engineering (Avli-Firis, 2018; Cemrek, 2011; Eskin, 2012; Isen, 2011; Ugurlu, 2004), industrial engineering (Kaymak, 2009; Oner, 2007), energy (Angin, 2005; Can, 2011; Damgaci, 2016; Grozdev, 2010; Kar, 2008; Khalkfan, 2015; Oz, 2006; Oz, 2013; Ozer, 2003; Yilmaz, 2012), physics engineering (Saritas, 2004), business (Nuran, 2014), chemistry (Acikgoz, 2001; Boz, 2011; Ozturk, 2010) and mechanical engineering (Kirec, 2009). 
Considering the studies conducted in the field of education, it was determined that the skill and success level and model proposal for teaching the subject. When the research groups were examined, it was determined that they focused on primary school students. However, there are no studies where the opinions and thoughts of gifted students are taken or executed projects about energy needs. Whereas, the metacognitive skills and equipment of gifted children (Cutts \& Moseley, 2004), their ability to produce scientific solutions to problems and to obtain the opinions of gifted children (Atak \& Atik, 2007) who have the potential to produce products are important both scientifically and economically.

Therefore, it was aimed to determine the mental models of gifted students for the concept of renewable energy resources in the research. Considering this purpose, the concept of a gifted individual, renewable energy resources, and mental model subjects are explained below.

\section{Which one is more correct? Gifted Individual or Talented Individual}

Although it has been stated that gifted individuals have a higher level of performance in the cognitive field compared to their peers (Sternberg, Jarvin \& Grigorenko, 2011) and that they have different needs than their peers' characteristics and needs (Tomlinson \& Hockett, 2008), there is no comprehensible and sharply defined conceptualization for the concept of "giftedness". Therefore, there are speculations about whether the individuals concerned will use the adjective gifted or talented. In response to the relevant speculation, the Ministry of National Education directive in 2016 states that individuals with creativity, leadership, and high-performance indicators should be expressed as talented (Guney, 2018). On the other hand, the educational processes of individuals with the specified characteristics should also be special. For this reason, acceleration, enrichment, grouping, and mentoring training services are provided for these individuals (Sak, 2014). Additionally, training is provided to support their skills, develop their skills, and gain their skills in science and art centers.

\section{Renewable Energy Resources}

Renewable energy resources are the name given to the sources that can be renewed and reused and are not exhausted (Tiwari \& Mishra, 2011). When the literature on renewable energy resources is examined, it is seen that renewable energy resources are grouped under five headings: solar energy, wave energy, wind energy, geothermal energy, and biomass energy (Edenhofer et al., 2011; Førsund, 2015; Mahmutoglu, 2013; Mertoglu, 2019). 
i) Solar Energy: Considering the importance of the sun in ensuring the continuity of the world and its effect on human health, it can be seen how important the sun and its energy are for humanity and science (Mertoglu, 2019). Additionally, it is also important to integrate the energy of the sun into daily life with panels and batteries (Mahmutoglu, 2013).

ii) Wave Energy: When the literature is examined for the concept of wave energy, the concepts of water energy and hydroelectric energy are encountered. While the tidal energies of seas or oceans at the surface or depths are called wave energy (Biyikli, 2018), the energy obtained by changing the flow of a stream or river is called hydroelectric energy (Førsund, 2015).

iii) Wind Energy: The airflow between the high-pressure and low-pressure areas is called wind. The acceptance of wind as a renewable energy resource depends on the continuity and repeatability of the airflow between the pressure areas (Elibuyuk \& Ucgul, 2014). Windmills, wind turbines, and sailing ships use wind energy (Kaya \& Kahraman, 2015).

iv) Geothermal Energy: Geothermal energy is obtained from warmer geothermal sources than underground waters and contains water vapor (Yorukoglu, 2014). Geothermal energy has positive features such as electricity generation and meeting the heating need depending on the earth's temperature (Kulunk, 2003). On the other hand, geothermal energy has negative features such as extracting from a depth of approximately 2000 meters and not being available in all regions (Edenhofer et al., 2011).

v) Biomass Energy: Biomass energy is the name given to the energy obtained by plant or animal wastes' physical and chemical processes. Because plant and animal wastes are not exhausted, they are considered renewable energy resources (Edenhofer et al., 2011).

\section{Mental Model}

The mental model concept, first expressed descriptively by Johnson-Laird in 1983, was described as creating analogies for the facts that people perceived or conceptualized (IyibilDurukan, 2019). Similar to the relevant description, Vosniadou (1994) emphasized the role of mental functions on analogical representations produced by individuals. Also, Franco and Colinvaux (2000) defined the mental model as thoughts by which people make sense of events and situations occurring in the world. According to the definitions, the patterns that individuals have formed in their minds due to their prior knowledge, thoughts, and acquisitions on the relevant subject are called mental models. Mental models should be 
carefully determined and evaluated because the patterns created are abstract in nature and based on behaviors that can only be observed (Rapp, 2005). Especially the fact that mental models are abstract leads to making false inferences and misconceptions (Eilam, 2004). Therefore, it will be important to research to determine the mental models of individuals regardless of the subject area and to eliminate the misconceptions and mistakes in mental models. Additionally, four properties of mental models are mentioned.

(i) Individuals can use their mental models to transfer them to new situations.

(ii) Individuals may not be aware that they use their mental models to transfer them to the new situation. So mental models can contain "silent information".

(iii) Individuals can benefit from both their experiences and scientific arguments in the process of creating their mental models. If there is such a structure, it may be necessary to talk about synthesis models.

(iv) Mental models possessed by individuals are affected by their beliefs. The worldview can be predicted by looking at the mental model of the individual (Franco \& Colinvaux, 2000).

Considering the characteristics and definitions of mental models, the mental models of individuals can be named as synthesis models or scientific models according to the existence of scientific knowledge. If there are experiences and arguments in the views of the individual, the synthesis model; If there are scientific facts and arguments against these facts in the views of the individual, it is necessary to talk about the scientific model.

\section{Method}

Method title of research were presented information on the research design, participants, data collection process and materials, data analysis, and validity and reliability.

\section{Research Design}

Which research design will be used in scientifically conducted research is important for the research to be meaningful. The most appropriate research design should be selected by considering the purpose of the research, problem situations, data collection process, and data collection tools (McMillan \& Schumacher, 2006). Considering these situations, the case study method was chosen as the research design. In selecting the case study method as the research design, (i) It is aimed to determine the mental models of gifted students for the concept of renewable energy sources in-depth, and (ii) to try to reveal the cause-effect 
relationship. Additionally, questions that such as "What?", "How?" and "Why?", were asked to the participants (Cepni, 2010). These questions are question types representing the case study method.

\section{Participants}

The study participants consisted of 14 students who study in the training programs of Individual Talent Recognition (ITR) in the Science and Art Center in Trabzon. These participants receive education at the same grade level. In selecting these participants who study in Science and Art Center in Trabzon, it was taken into consideration that the subject of renewable energy sources is at the appropriate class level. Although a total of 28 students are studying in the ITR program of the Science and Art Center, 14 students were selected according to the voluntary factor in the research process. According to ethical rules, codes such as $\mathrm{S} 01, \mathrm{~S} 02, \ldots \mathrm{S} 14$ were used instead of the names of the participants.

\section{Data Collection Process and Materials}

The data of the research were collected from participants through clinical interviews. Clinical interviews are a technique that is used to examine the cognitive thinking processes people have about situations, events, phenomena, or issues in-depth and can reveal mental models thanks to their flexible asking questions (Clement, 2000). The preference of clinical interviews during the research process effectively revealed mental models (Baki, Karatas \& Guven, 2002) and provided the opportunity to examine the process in depth thanks to the possibility of asking flexible questions (Karatas \& Guven, 2003). Clinical interviews were conducted approximately 15-20 minutes of interviews, and their voices were recorded with the participants' permission. After the obtained data was transferred to the computer, the analysis processes were carried out, and then participants' voices were deleted by ethical rules.

\section{Data Analysis}

The data obtained from the participants were analyzed using the computer-aided qualitative data analysis program NVivo 10. Content analysis technique was used in the analysis process. The content analysis technique provides an opportunity to create specific themes while establishing the connection between concepts, which includes separating the data obtained from the participants about a subject area into codes, categories, and themes (Buyukozturk et al., 2011).

\section{Validity and Reliability}


Participant confirmation and expert opinion were consulted to ensure the validity factor of the study. The data obtained from the participants were presented to the participants after the analysis process, and their confirmation was received. After the confirmation process, an academician who was an expert in the qualitative data analysis process was obtained, and the validity factor of the research was tried to be obtained. The harmony between the analysis made by two different researchers was taken into account for the reliability factor of the study. In the qualitative data analysis process, the researchers carried out the coding process separately. The reliability factor was provided with similar coding and different coding by researchers. The ratio of similar coding and different coding is an important value for the reliability factor.

\section{Findings}

The data obtained from the data collection tool used to determine the mental models of gifted students for the concept of renewable energy resources were evaluated under the headings of the concept of energy and energy resources, types of renewable energy resources, reasons of need for renewable energy resources, and recommendations for the use of renewable energy resources.

\section{The Concept of Energy and Energy Resources}

Gifted students were asked and were taken their opinions about the concept of energy and energy resources. The questions, "What is energy?", "What are the concepts that come to mind when you hear the concept of energy?", "What are the energy sources?", "What are the concepts that come to mind when you hear the concept of energy resources?" and "What are called energy sources?", were asked to gifted students. With these questions, gifted students' opinions about the concept of energy and energy resources were determined. 
Table 1. The opinions of gifted students about energy and energy resources

\begin{tabular}{|c|c|c|c|}
\hline Theme & Code & Frequency & Percent \\
\hline \multirow{5}{*}{ Energy } & Force & 8 & 24,24 \\
\hline & Motion & 7 & 21,21 \\
\hline & Power & 10 & 30,30 \\
\hline & Heat and Light & 5 & 15,15 \\
\hline & Electricity & 3 & 9,09 \\
\hline \multirow{5}{*}{ Energy Resources } & Fossil Fuel Energy & 7 & 18,91 \\
\hline & Solar Energy & 13 & 35,13 \\
\hline & Nuclear Energy & 5 & 13,51 \\
\hline & Wind Energy & 11 & 29,72 \\
\hline & Boron Energy & 1 & 2,70 \\
\hline
\end{tabular}

When Table 1 is examined, the opinions of gifted students about energy and energy resources are seen that the concept of energy has five different sub-concepts: force, motion, power, heat and light, and electricity. Associating the concept of energy with the concept of power, the participant (S03) expressed his/her opinion as "When energy is mentioned, the first thing that comes to my mind is power in every sense". Relating the concept of energy with the concept of force, the participant (S06) expressed his/her opinion as "Energy is a type of force. As a result of the force applied by the energy, energy can be felt by people". Correlating the concept of energy with the concept of motion, the participant (S02) expressed his/her opinion as "Energy is what is spent or earned when it moves". Affiliating the concept of energy with the concept of heat and light, the participant (S11) expressed his/her opinion as "Many household appliances can be used with the energy created by heat and light". Associating the concept of energy with the concept of electricity, the participant (S09) expressed his/her opinion as "Since it is the concept of electrical energy, energy coincides with electricity". The fact that conceptual relationships are included in the participants' mental models for the concept 
of energy indicates the existence of scientific knowledge. This situation reveals that the participants have synthesis models or scientific models.

It is seen that they describe the concept of energy resources with five different concepts: fossil fuel energy, solar energy, nuclear energy, wind energy and boron energy. Associating the concept of energy resources with the concept of solar energy, the participant (S01) expressed his/her opinion as "Considering the solar panels that I have been started to see even on the roofs of houses, the sun comes to mind as an energy resource". Relating the concept of energy resources with the concept of wind energy, the participant (S07) expressed his/her opinion as "I saw it on a hill in Izmir. The wind produced energy". Correlating the concept of energy resources with the concept of fossil fuel energy, the participant (S04) expressed his/her opinion as "I can talk about fuels such as gasoline, diesel oil and natural gas as energy resources". Affiliating the concept of energy resources with the concept of nuclear energy, the participant (S05) expressed his/her opinion as "I can talk about fuels such as gasoline, diesel oil and natural gas as energy resources". Associating the concept of energy resources with the concept of boron energy, the participant (S14) expressed his/her opinion as "The boron energy obtained from the boron element, which is mostly found in the soils of our country, can be expressed".

Participants' mental models about energy resources include renewable energy sources, non-renewable energy sources, and alternative energy resources. Depending on this situation, mental models of gifted students can have evolved into synthesis models or scientific models.

\section{The Types of Renewable Energy Resources}

Gifted students were asked and were taken their opinions about renewable energy resources. The questions, " What are the renewable energy resources?", " What are the concepts that come to mind when you hear the concept of renewable energy sources?" and "What are the types of renewable energy resources?", were asked to gifted students. With these questions, gifted students' opinions about renewable energy resources were determined. 


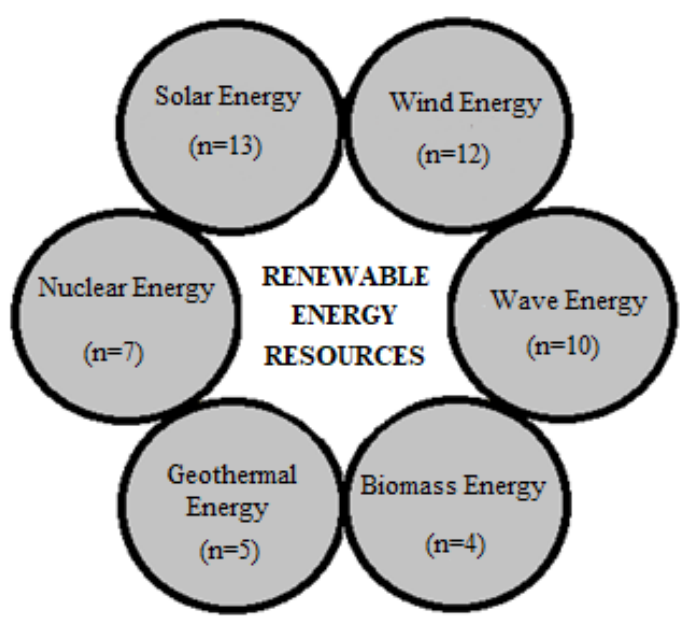

Figure 1. The opinions of gifted students about renewable energy resources' types

When Figure 1 is examined, the opinions of gifted students about renewable energy sources' types seen that the renewable energy resources' types have six different sub-concepts: solar energy, wind energy, wave energy, biomass energy, geothermal energy, nuclear energy. Emphasizing the concept of solar energy, which is one of the types of renewable energy resources, the participant (S08) explained his/her opinion as follows: "When it comes to renewable energy sources, the first thing that comes to my mind is the sun. I think the energy provided by the sun is very important". Accenting the concept of wind energy, which is one of the types of renewable energy resources, the participant (S10) explained his/her opinion as follows: "When we were children, we used to make windmills from wood. I always thought if we could hook a light bulb behind it when it turns with the wind". Accentuating the concept of wave energy, which is one of the types of renewable energy resources, the participant (S12) explained his/her opinion as follows: "Since our country is surrounded by water on three sides, it is necessary to give importance to energy production by using water". Highlighting the concept of nuclear energy, which is one of the types of renewable energy resources, the participant (S13) explained his/her opinion as follows: "Although a large part of the society opposes it, nuclear energy comes first among the renewable energy resources". Underlining the concept of geothermal energy, one of the types of renewable energy resources, the participant ( $\mathrm{S} 02)$ explained his/her opinion as follows: "Geothermal energy can be given as an example of using groundwater effectively and contributing to energy production". Emphasizing the concept of biomass energy, which is one of the types of renewable energy resources, the participant (S07) explained his/her opinion as follows: "Last year we designed a project with our chemistry teacher. We aimed to obtain a gas from waste materials and use it as energy. This is called biomass energy". The opinions of gifted students about renewable energy resources' types included 
solar energy, wave energy, wind energy, biomass energy, geothermal energy, and nuclear energy. Solar energy, wave energy, wind energy, biomass energy, and geothermal energy are renewable energy resources, but nuclear energy is not. Depending on this situation, the mental models of gifted students about renewable energy resources have a misconception.

\section{Reasons of Need for Renewable Energy Resources}

Gifted students were asked and were taken their opinions about the need for renewable energy resources. The questions, "Why are renewable energy sources needed?" and "What are the reasons for the need for renewable energy sources?" were asked gifted students. With these questions, gifted students' opinions about reasons of need for renewable energy resources were determined.

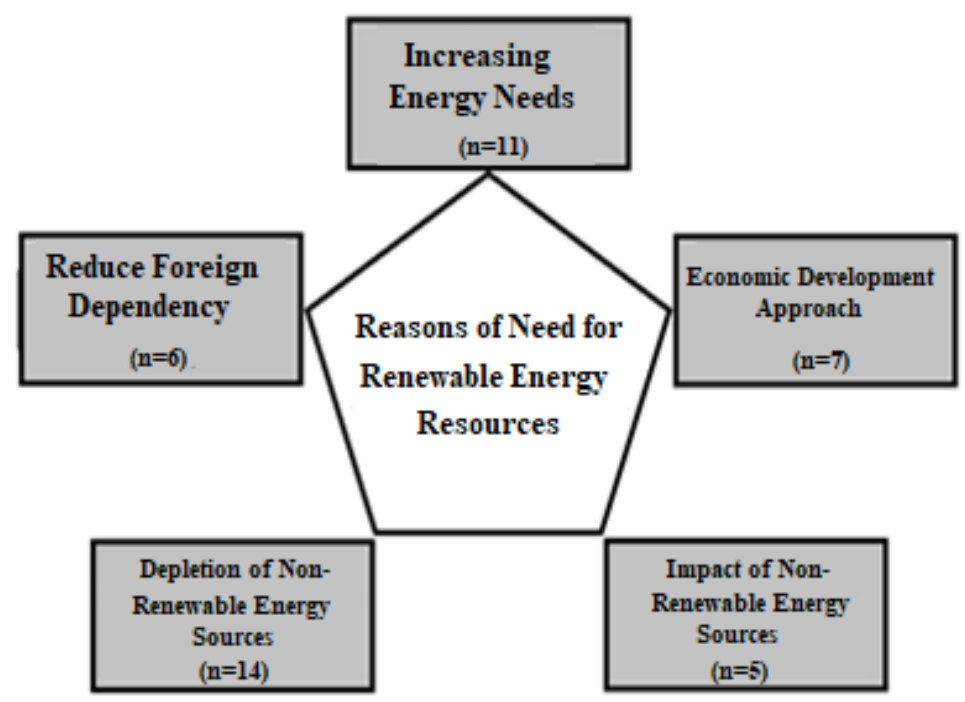

Figure 2. The opinions of students about reasons of need for renewable energy resources

When Figure 2 is examined, the opinions of gifted students about reasons of need for renewable energy sources seen that the reasons of need for renewable energy resources have five different sub-concepts: increasing energy needs, economic development approach, the impact of non-renewable energy resources on the environment, depletion of non-renewable energy sources and reduce foreign dependency. Expressing the concept of increasing energy needs, which is one of the reasons for the need for renewable energy resources, the participant (S09) described his/her opinion as follows: "Technological developments have increased the need for energy. For example, I always try to sit near the wall socket at school for phone charging". Stating the concept of economic development approach, which is one of the reasons for the need for renewable energy resources, the participant (S12) described 
his/her opinion as follows: "It takes money to be among the leading countries. Too many factors are needed for the economy for money. One of them is energy". Articulating the concept of the impact of non-renewable energy resources on the environment, which is one of the reasons of need for renewable energy resources, the participant (S13) described his/her opinion as follows: "Toxic gases produced by fuels such as petrol, diesel and natural gas harm the environment". Verbalizing the concept of depletion of non-renewable energy sources, which is one of the reasons for the need for renewable energy resources, the participant (S06) described his/her opinion as follows: "The depletion of fossil fuels has led to the use of other energy sources." Phrasing the concept of reducing foreign dependency, which is one of the reasons for the need for renewable energy sources, the participant (S01) described his/her opinion as follows: "As a country, we are dependent on foreign countries in many areas. If we have energy resources, we can get away from loyalties". Participants' mental models about reasons for the need for renewable energy resources were interpreted scientific knowledge and understanding of economic awareness. Depending on this situation, the mental models of gifted students have evolved into scientific models.

\section{Recommendations for the Use of Renewable Energy Resources}

Gifted students were asked and were taken their opinions about recommendations for the use of renewable energy resources. The questions, "What are the suggestions for renewable energy resources?" and " How can renewable energy sources be used more effectively?" were asked to gifted students. With these questions, gifted students' opinions about recommendations for the use of renewable energy resources were determined. 


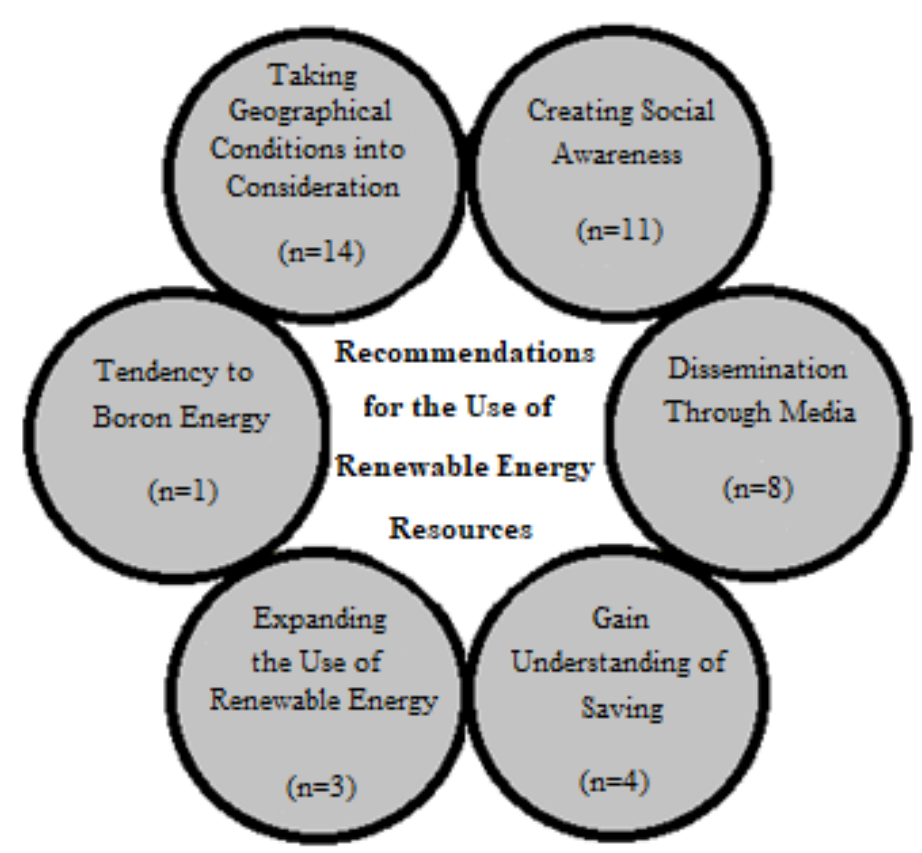

Figure 3. Recommendations of Gifted Students for the Use of Renewable Energy Resources

When Figure 3 is examined, the recommendations of gifted students for the use of renewable energy resources seen that the recommendations for the use of renewable energy resources have six different sub-concepts: creating social awareness, dissemination through media, gain an understanding of saving, expanding the use of renewable energy, the tendency to boron energy and considering geographical conditions. Declaring the concept of creating social awareness, which is one of the recommendations of gifted students for the use of renewable energy resources, the participant (S11) described his/her opinion as follows: "We see it in the movies before the hydroelectric power plants are established, public awareness is made. Lessons should be given to the society about renewable energy sources". Explaining the concept of dissemination through media, which is one reason for the need for renewable energy resources, the participant (S08) described his/her opinion as follows: "I think it would be beneficial to mention renewable energy sources in public awareness advertisements". Affirming the concept of gain understanding of saving, which is one of the reasons for the need for renewable energy resources, the participant (S04) described his/her opinion as follows: "It is necessary to meet the energy need. The idea of how we can use the buildings more economically should be widespread and used.". Proclaiming the concept of expanding the use of renewable energy, which is one of the reasons for the need for renewable energy resources, the participant (S01) described his/her opinion as follows: "It is necessary to turn towards renewable energy sources not only for electricity generation but also for other types of energy". Announcing the concept of a tendency to boron energy, which is one 
of the reasons of need for renewable energy resources, the participant (S04) described his/her opinion as follows: "Turn to the most important mineral boron resources we have in Turkey must be provided. I am sure that by using boron mineral, energy needs in various fields can be met easily". Asserting the concept of taking geographical conditions into consideration, which is one of the reasons for the need for renewable energy resources, the participant (S03) described his/her opinion as follows: "Considering the regional differences, it should be ensured that energy resources are used and expanded according to the characteristics of the region. Water should be used in places near the sea, and wind should be used in higher parts". When the participants' recommendations for the use of renewable energy resources are interpreted, it is necessary to consider the geographical conditions and expand the areas of use. In addition, views such as establishing social awareness, understanding saving, making it widespread through media organs, and ensuring the use of boron mineral attract attention.

\section{Discussion}

The obtained data which was conducted to determine the mental models of gifted students for the concept of renewable energy resources are presented under four headings: the concept of energy and energy resources, the types of renewable energy resources, reasons for the need for renewable energy resources, and recommendations for the use of renewable energy resources.

When the mental models of gifted students regarding energy and energy resources are examined, it is seen that they include associative concepts such as power, force, and motion and cannot define energy in a conceptual dimension. Similarly, in mental models for energy resources, alternative sources such as nuclear energy and boron are expressed as well as renewable and non-renewable energy resources. In the study conducted by Sarac and Bedir (2014) on energy resources, it was revealed that the participants emphasized wind, solar, and wave energy, similar to the data obtained in this research. The data obtained in the study conducted by Biyikli (2018) to examine the opinions of teachers and teacher candidates on renewable energy and the data obtained from this research show parallelism in the types of energy resources in terms of fossil renewable fuels energy resources. Similarly, in the study conducted by Cebesoy and Karisan (2017), it was determined that the participants mostly mentioned the concept of solar energy. It is thought that the importance of the sun for humanity and life as well as the scientific studies carried out on solar energy in a way that individuals can observe and concretize affect the similarity of the data obtained from this research and the literature especially the importance of solar energy. Situations 
such as the increase in solar panels and electronic devices working with solar energy, which can be seen on the roofs of houses in almost every region, support this idea. For this reason, it would not be wrong to expect the concept of the sun to emerge in the studies conducted or to be carried out for energy resources.

When the mental models of gifted students for the types of renewable energy resources are examined, it is seen that they also touch on the concepts of solar energy, wave energy, wind energy, biomass energy, and geothermal energy. In the study conducted by Karakaya-Cirit (2017), the participants mentioned the concepts of biomass energy, geothermal energy, wave energy, and nuclear energy and addressed the concepts of solar and wind energy intensely. In the study conducted by Gul-Elmas (2018) to examine the mental structures of secondary school students in the subject area of renewable energy resources, it was observed that the students mentioned the types of renewable energy resources expressed within the scope of the research. Similarly, in the study conducted by Kilicaslan, Aymen Peker, and Gun (2011), it was determined that the participants had information about the types of renewable energy resources and expressed the types of renewable energy resources. It is thought that scientific and economic studies conducted by understanding renewable energy and sustainable development affect the similarity between the data obtained from the research and the literature. Creating public spot broadcasts for the internalization of the concept of saving together with visual and audio media, the inclusion of energy need and the understanding of sustainable development as a subject area in the education process and the practices carried out in line with the idea of economic development, which is socially seen as a global goal, support this idea. On the other hand, it is seen that the participants also touched on the concept of nuclear energy in their mental models. Considering the element used in nuclear energy generation and the reaction situation that occurs, it should not be included under the relevant heading. However, its presence under this heading is determined as a mistake in the participants' mental models.

When the mental models of gifted students regarding the reasons for the need for renewable energy resources are examined, the scientific factors such as the depletion of nonrenewable energy resources, the increase in energy need and the impact of non-renewable energy resources on the environment; The fact that they expressed concepts such as reducing external dependency and economic development also reveals the effect of economic factors on their mental models. In the research conducted by Cakirlar (2015) to determine the awareness of secondary school students in renewable energy resources, the gradual decrease 
in natural resources and the increase in the need of energy were indicated by emphasizing its importance for the country. It is thought that the emergence of energy needs due to the development of science and technology and the implementation of the process by choosing fossil fuels called non-renewable energy resources to meet this energy need affect the emergence of related ideas. In the period known as the technology or science age, energy is needed in all materials such as phones, computers, computers, and white goods, which are technological tools used by people (Deviren, Ilkilic, \& Aydin, 2017). The fact that fossil fuels are preferred primarily to meet the relevant needed situation reveals concepts such as exhaustibility, non-renewability, usefulness, and efficiency. Considering the burden of the related concepts on societies, it can be said that societies divest from fossil fuels and tend to renewable resources such as sun and wind (Ucgul \& Elibuyuk, 2016). Therefore, societies that want to eliminate the burden and have a political voice by developing both scientifically and economically are turning to renewable energy resources (Altun \& Isleyen, 2018; Ozcan, Unlusoy \& Eren, 2017).

When the suggestions of gifted students regarding the use of renewable energy resources are examined, it is suggested that other stakeholders should be included in the process, such as taking into account the geographical conditions and expanding the areas of use, creating social awareness for the use of renewable energy resources, gaining an understanding of savings, and making dissemination through media organs. Geographical conditions should be considered to divest renewable energy resources correctly and feasibly to meet the energy need. It can be said that energy production should be provided by using wave energy, especially in our country, which is surrounded on three sides by the sea. Similarly, in the Mediterranean and Southeastern Anatolia regions where the temperature is high, the Aegean Region has a potentially good place in terms of solar energy (solar panels, etc.) and wind energy (wind turbines, etc.) Providing the necessary conditions in terms of infrastructure opportunities and continuing the energy production process is important for the present and future of our country. In addition, although it is not considered a renewable energy source, mental models for evaluating alternative methods such as ensuring the use of boron mineral is also remarkable. 


\section{Conclusion}

- When the opinions of gifted students about energy and energy resources are examined, it is seen that there are deficiencies and inaccuracies in their mental models. In order to overcome this problem, support training should be provided in the education process so that the mental models of gifted students can become scientific models.

- When the opinions of gifted students about the types of renewable energy sources are analyzed, they expressed the concepts of solar energy, wind energy, biomass energy, geothermal energy, wave energy, and nuclear energy. Project implementations should be carried out to internalize the type of renewable energy resources and resolve energy needs.

- According to the opinions of gifted students, the reasons for the need for renewable energy resources are the increased energy need and the depletion of the energy resources used. It is recommended to adopt the understanding of sustainable development and structure the idea of saving in a socially meaningful way and provide the orientation towards renewable energy resources for increasing energy need.

- When the opinions of gifted students about renewable energy sources are examined, it has been suggested to use resources according to geographical conditions and raise social awareness. The rationale for this recommendation is to ensure that resources can be used more efficiently and effectively. It is thought that it would benefit researchers who plan to carry out studies about energy needs.

Ethical Approval: This research was conducted with the permission of the Trabzon University Social Sciences and Humanities ethics committee with decision no 81614018-50 dated 13.11.2018.

Conflict Interest: The authors declare no conflict of interest.

Authors Contributions: The authors declare that they have contributed equally to the article.

\section{References}

Acikgoz, C. (2001). Researching of linseed as an alternative energy sources. Unpublished doctoral dissertation, Anadolu University, Eskisehir, Turkey.

Alagoz, B. (2005). A unit model suggestion for teaching renewable (alternative) energy sources at middle school social students lesson. Unpublished master's thesis, Gazi University, Ankara, Turkey. 
Altun, Y. \& Isleyen, S. (2018). An empirical study on tendency to electricity production from renewable energy resources in some OECD countries. Ataturk University Journal of Social Sciences Institute, 22(3), 1577-1590.

Angin, D. (2005). Evaluation of safflower (Charthamus tinctorius L.) seed cake as an alternative energy source. Unpublished doctoral dissertation, Eskisehir Osmangazi University, Eskisehir.

Atak, M. \& Atik, I. (2007). The importance of continuous education in organizations and its effect on the learning organization process. Journal of Aeronautics and Space Technologies, 3(1), 63-70.

Avli-Firis, F. (2018). Alternative energy production for signalization systems. Unpublished master's thesis, Kahramanmaras Sutcu İmam University, Kahramanmaras.

Ayran, K. (2015). Analysis of alternative energy sources in Turkey economic point of view. Unpublished master's thesis, Cankiri Karatekin University, Cankiri.

Baki, A., Karatas, I. \& Guven, B. (2002, September). Evaluation of problem-solving skills with clinical interview method. V. National Science and Mathematics Education Congress, METU, Ankara.

Biyikli, D. (2018). Examining the opinions of the pre-service and on-duty teachers towards renewable energy sources. Unpublished master's thesis, Mersin University, Mersin.

Boz, O. H. (2011). Current alternative energy resource: Photovoltaic solar cells. Unpublished master's thesis, Balikesir University, Balikesir.

Buyukozturk, S., Kilic Cakmak, E., Akgun, O. E., Karadeniz, S. \& Demirel, F. (2011). Bilimsel arastirma yontemleri (8th Edition). Ankara: PEGEM Academy.

Can, S. (2011). Managing potential of alternative energy sources: The case of Canakkale province. Unpublished master's thesis, Canakkale Onsekiz Mart University, Canakkale.

Cebesoy, U. B. \& Karisan, D. (2017). Investigation of preservice science teachers' knowledge, teaching efficacy perceptions and attitude towards renewable energy sources. YYU Journal of Education, 14(1), 1377-1415. 
Clement, J. (2000). Analysis of clinical interviews: Foundation and model viability. In A. E. Kelly \& R. Lesh (Eds.), Handbook of research design in mathematics and science education (pp. 547-589). New Jersey: Lawrence Erlbaum.

Cutts, N. E. \& Moseley, N. (2004). Ustun zekali ve ustun yetenekli cocuklarin egitimi: Ulusun en buyuk kaynaklarindan birinin harcanmasi nasil önlenir (Translator: Ismail Ersevim). Istanbul: Ozgur Publications.

Cakirlar, E. (2015). Determining high school students' levels of awareness about renewable energy sources. Unpublished master's thesis, Hacettepe University, Ankara.

Cemrek, S. (2011). Evaluation of chestnut and apricot kernel shell as an alternative energy source. Unpublished master's thesis, Eskisehir Osmangazi University, Eskisehir.

Cepni, S. (2010). Arastirma ve proje calismalarina giris. Trabzon: Celepler Printing.

Damgaci, E. (2016). Evaluation of alternative energy sources by intuitionistic fuzzy Topsis method. Unpublished master's thesis, Gazi University, Ankara.

Deviren, H., Ilkilic, C. \& Aydin, S. (2017). Usable materials in the production biogas and using fields of biogas. Batman University Journal of Life Sciences, 7(2), 79-89.

Dogan, Y. (2011). Frequency of implementation of constructivist activities envisioned to be conducted in science and technology lessons. Journal of Theoretical Educational Science, 4(1), 18-37.

Edenhofer, O., Pichs-Madruga, R., Sokona, Y., Seyboth, K., Kadner, S., Zwickel, T., ... \& Matschoss, P. (2011). Renewable energy sources and climate change mitigation: Special report of the intergovernmental panel on climate change. New York: Cambridge University Press.

Eilam, B. (2004). Drops of water and of soap solution: Students' constraining mental models of the nature of matter. Journal of Research in Science Teaching, 41(10), 970-993.

Elibuyuk, U. \& Ucgul, I. (2014). Wind turbines, types and methods of wind energy storage. Suleyman Demirel University Journal of Yekarum, 2(3), 1-14.

Ergin, A. (2010). The effects of alternative energy sources education programme on the primary school seventh grade students' problem solving abilities and success levels. Unpublished master's thesis. Yeditepe University, Istanbul. 
Eskin, A. (2012). Analysis of the multilevel inverters for renewable energy systems. Unpublished master's thesis, Yildiz Technical University, Istanbul.

Førsund, F. R. (2015). Hydropower economics. New York: Springer.

Franco, C. \& Colinvaux, D. (2000). Grasping mental models. In J. K. Gilbert, \& C. J. Boulter (Eds.), Developing models in science education (pp. 93-118). New York: Springer.

Greca, I. M. \& Moreira, M. A. (2000). Mental models, conceptual models, and modelling. International Journal of Science Education, 22(1), 1-11.

Grozdev, M. (2010). Alternative energy resources: Solar energy and solar cells. Unpublished master's thesis. Istanbul University, Istanbul.

Gul-Elmas, O. (2018). The analysis of the cognitive structures of the 6th grade students about renewable energy. Unpublished master's thesis, Mersin University, Mersin.

Guner, C. (2016). Solution of current deficit and unemployment problems with the alternative energy sources, Turkey example. Unpublished master's thesis. Cumhuriyet University, Sivas.

Gunes, T., Alat, K. \& Gozum, C. A. I. (2013). Renewable energy sources attitude scale for science teachers: Validity and reliability study. Journal of Educational Sciences Research, 3(2), 269-289.

Guney, K. K. (2018). Evaluation of the differentiated research methods curriculum that developed for gifted students. Unpublished doctoral dissertation, Karadeniz Technical University, Trabzon.

Ifat, M. (2018). Domestic energy poverty and willingness to pay for alternative energy: The case of Pakistan. Unpublished master's thesis, Sabanci University, Istanbul.

Isen, E. (2011). Development of a grid connected three phase inverter system with low harmonics and high efficiency for renewable energy sources. Unpublished doctoral dissertation, Yildiz Technical University, Istanbul.

Iyibil-Durukan, U. G. (2019). The effect of designed adidactic situations on the university students' development of the mental models about electric current subjects. Unpublished doctoral dissertation, Trabzon University, Trabzon. 
Kar, Y. (2008). The investigation of black cumin (Nigella sativa L.) seed as the resource of natural antioxidant and alternative energy. Unpublished doctoral dissertation, Selcuk University, Konya.

Karakaya-Cirit, D. (2017). Pre-service science teachers' knowledge involving the topic of renewable energy sources. Turkish Journal of Educational Studies, 21-43.

Karatas, I. \& Guven, B. (2003). Methods used to evaluate problem solving behaviors: Potential of clinical interview. Elementary Education Online, 2, 2-9.

Kaya, T. \& Kahraman, C. (2010). Multicriteria renewable energy planning using an integrated fuzzy VIKOR \& AHP methodology: The case of Istanbul. Energy, 35(6), 2517-2527.

Kaymak, M. E. (2009). Development of alternative sources of energy in the 20.th century and in the parallel effects to the automobile design. Unpublished master's thesis, Anadolu University, Eskisehir.

Khalkfan, O. M. (2015). Alternative energy generation from the weights of moving vehicles. Unpublished doctoral dissertation, Selcuk University, Konya.

Kilicaslan, M., Aymen-Peker, E. \& Gun, F. (2011, October). Views of primary school students on the contribution of renewable energy sources to the environment: The Case of Samsun Province. Samsun Congress, Ondokuz Mayis University, Samsun.

Kirec, L. (2009). Building and experimental analysis of a polymer electrolyte membrane fuel cell as an alternative power source for vehicles with changing different parameters. Unpublished master's thesis, Gazi University, Ankara.

Koc, E. \& Senel, M. C. (2013). The state of energy in World and Turkey - General evaluation. Engineer and Machinery, 54(639), 32-44.

Kulunk, I. (2013). The relationship between energy consumption and economic growth within the context of energy efficiency and carbon emmissions: The case of Turkey. Unpublished master's thesis, Abant Izzet Baysal University, Bolu.

Mahmutoglu, M. (2013). The role of renewable energy at the electricity sector of Turkey. Unpublished master's thesis, Gazi University, Ankara.

McMillan, J. H. \& Schumacher, S. (2006). Research in education: Evidence-based inquiry. Boston: Pearson Education. 
Mertoglu, C. (2019). Determination of university students' awareness levels on renewable energy resources. Unpublished master's thesis, Ondokuz Mayis University, Samsun.

Nuran, M. (2014). Marine engineering economics: A cost comparative analysis for the alternative energy sources. Unpublished doctoral dissertation, Dokuz Eylul University, Izmir.

Oner, U. (2007). Alternative energy sources of Turkey and research of boron's industrial usage fields. Unpublished master's thesis, Istanbul Commerce University, Istanbul.

Oz, E. (2013). Analysis of alternative energy options and sustainability assessment for buildings. Unpublished master's thesis, Suleyman Demirel University, Isparta.

Oz, M. E. U. (2006). Determination of residential energy consumption characteristics and comparison fuel cells with alternative energy systems for the houses in Bursa. Unpublished doctoral dissertation, Uludag University, Bursa.

Ozcan, E. C., Unlusoy, S. \& Tamer, E. (2017). Evaluation of the renewable energy investments in Turkey using ANP and TOPSIS methods. Konya Journal of Engineering Sciences, 5(2), 204-219.

Ozer, S. (2003). Air pollution problem and alternative energy sources at Bursa. Unpublished master's thesis, Uludag University, Bursa.

Ozkaya, S. Y. (2017). Renewable energy sources. Ankara: Republic of Turkey Ministry of Foreign Affairs.

Ozturk, Z. (2010). The synthesis of metal organic framework with vinylpyridine and their hydrogen, an alternative energy source, storage properties. Unpublished master's thesis, Ondokuz Mayis University, Samsun.

Rapp, D. N. (2005). Mental models: Theoretical issues for visualizations in science education. In J. K. Gilbert (Ed.), Visualization in science education (pp. 43-60). Netherlands.

Republic of Turkey Ministry of Energy and Natural Resources (2017). World and Turkey's energy and natural resources view, Ankara.

Sak, U. (2014). Ustun zekalilar: Ozellikleri, tanılanmalarl, egitimleri. (4th Edition). Ankara: Vize Publishing. 
Sarac, E. \& Bedir, H. (2014). Primary school teachers related to perceptions of renewable energy sources on the qualitative research. The Journal of Defence and War Studies, $24(1), 19-45$.

Saritas, F. (2004). As alternative source usage in the fuel cells, application fields, importance of hydrogen in the future. Unpublished master's thesis, Eskisehir Osmangazi University, Eskisehir.

Sternberg, R. J., Jarvin, L. \& Grigorenko, E. L. (2011). Explorations in giftedness. Cambridge University Press: New York.

Tekesin, C. (2011). Estimation of willingness to pay for alternative energy sources in Turkey. Unpublished master's thesis, Hacettepe University, Ankara.

Tiwari, G. N. \& Mishra, R. K. (2012). Advanced renewable energy sources. London: RSC Publishing.

Tomlinson, C. A. \& Hockett, J. A. (2008). Instructional strategies and programming models for gifted learners. In F. A. Karnes \& K. R. Stephens (Eds.), Achieving excellence: Educating the gifted and talented (pp. 154-169). Upper Saddle River, NJ: Pearson.

Ucak, S. (2010). Alternative energy in the regard of sustainable development and energy production growth relationship: Panel-data analysis. Unpublished doctoral dissertation, Kocaeli University, Kocaeli.

Ucgul, I. ve Elibuyuk, U. (2016). Renewable energy sources and energy geopolitics. Anka eJournal Social Sciences and Technology Journal, 2(1), 26-33.

Ugurlu, M. (2004). Alternative energy sources, wind energy and its realization. Unpublished master's thesis, Sakarya University, Sakarya.

Vosniadou, S. (1994). Capturing and modelling the process of conceptual change. Learning and Instruction, 4, 45-69.

Yamak, T. (2006). The potential of Turkey's renewable energy resources and economical analysis. Unpublished master's thesis, Marmara University, Istanbul.

Yasar, B. (2009). Evaluation of biodiesel production and utilization of biodiesel as an alternative source of energy from the point of view of Turkish agriculture and EU adaptation process. Unpublished doctoral dissertation, Cukurova University, Adana. 
H S, Ayvaci, M, Kucuk \& G, Bebek / Pamukkale University Journal of Education, 53, 378-402, 2021

Yilmaz, A. (2012). Factors effect sectoral energy consumption in Turkey and alternative energy policies. Unpublished doctoral dissertation, Adnan Menderes University, Aydin.

Yorukoglu, H. (2014). The analysis of the risks of renewable energy resources by using Fuzzy-FMEA technique. Unpublished master's thesis, Kocaeli University, Kocaeli. 